\title{
GNREL
}

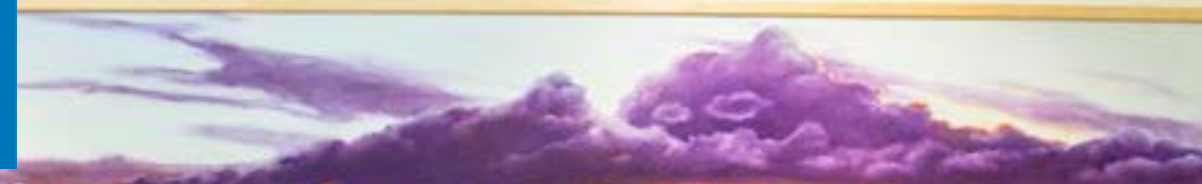

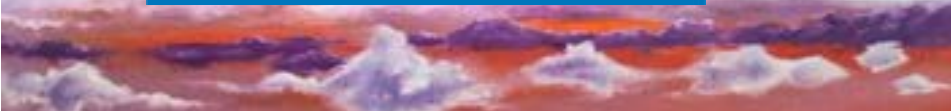

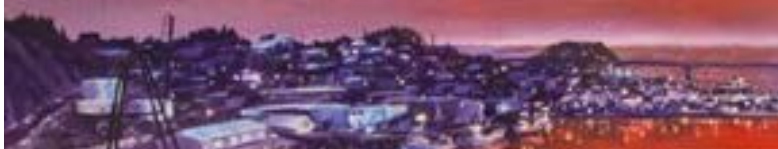

\section{Renewable Portfolio Standard Assessment for Alaska's Railbelt}

\author{
Paul Denholm, Marty Schwarz, Elise DeGeorge, \\ Sherry Stout, and Nathan Wiltse
}

NREL is a national laboratory of the U.S. Department of Energy Office of Energy Efficiency \& Renewable Energy

Operated by the Alliance for Sustainable Energy, LLC

This report is available at no cost from the National Renewable Energy Laboratory (NREL) at www.nrel.gov/publications.
Technical Report

NREL/TP-5700-81698

February 2022 


\title{
GNREL
}

\section{Renewable Portfolio Standard Assessment for Alaska's Railbelt}

\author{
Paul Denholm, Marty Schwarz, Elise DeGeorge, \\ Sherry Stout, and Nathan Wiltse
}

\section{Suggested Citation}

Denholm, Paul, Marty Schwarz, Elise DeGeorge, Sherry Stout, and Nathan Wiltse. 2022.

Renewable Portfolio Standard Assessment for Alaska's Railbelt. Golden, CO: National

Renewable Energy Laboratory. NREL/TP-5700-81698.

https://www.nrel.gov/docs/fy22osti/81698.pdf.

NREL is a national laboratory of the U.S. Department of Energy Office of Energy Efficiency \& Renewable Energy Operated by the Alliance for Sustainable Energy, LLC

This report is available at no cost from the National Renewable Energy Laboratory (NREL) at www.nrel.gov/publications.

Contract No. DE-AC36-08GO28308
Technical Report

NREL/TP-5700-81698

February 2022

National Renewable Energy Laboratory 15013 Denver West Parkway Golden, CO 80401

303-275-3000 • www.nrel.gov 


\section{NOTICE}

This work was authored by the National Renewable Energy Laboratory, operated by Alliance for Sustainable Energy, LLC, for the U.S. Department of Energy (DOE) under Contract No. DE-AC36-08GO28308. Internal funding was provided by the National Renewable Energy Laboratory. The views expressed herein do not necessarily represent the views of the DOE or the U.S. Government.

This report is available at no cost from the National Renewable Energy Laboratory (NREL) at www.nrel.gov/publications.

U.S. Department of Energy (DOE) reports produced after 1991 and a growing number of pre-1991 documents are available free via www.OSTI.gov.

Cover Photo by Dennis Schroeder: NREL 51227.

NREL prints on paper that contains recycled content. 


\section{Acknowledgments}

This work would not have been possible without the very helpful collaboration, input, and data provided by numerous stakeholders across Alaska, including (alphabetized):

- Alaska Energy Authority: David Lockard, Kirk Warren, Conner Erickson, Brian Carey, and Josephine Hartley

- Chugach Electric Association: Arthur Miller, Dustin Highers, Sean Skaling, and Kate Ayers

- City of Seward Utilities: Rob Montgomery

- Golden Valley Electric Association: John Burns, John Kelly, Naomi Knight, Corrine Taylor, Abbigail Dillard, and the Golden Valley Electric Association Board

- Homer Electric Association: Mike Salzetti

- Matanuska Electric Association: Edward Jenkin, Jon Sinclair, Julie Estey, and Erica Wilson

- Office of the Governor: Jordan Shilling, Tyler Sachtleben

- Renewable Energy Alaska Project: Chris Rose and Rob Jordan

We would also like to thank (alphabetized by first name):

- Brian Despard, 1898 \& Co.

- David Burlingame, Electric Power Systems, Inc.

- Devany Plentovich, Deerstone Consulting

- Doug Johnson, Ocean Renewable Power Company

- Erin McKittrick and Hig Higman, Ground Truth Trekking

- Joel Groves. Polarconsult Alaska, Inc.

- Matt Perkins and Andrew McDonnell, Alaska Renewables LLC

- Michael Hubbard, Financial Engineering Company

- Mike Craft, Alaska Environmental Power

- Nick Goodman, Cyrq Energy

- Rob Roys, Launch Alaska

- Sam Dennis, Renewables IPP

- Scott Waterman

- Stephen Trimble, Arctic Solar Ventures

- Suzanne Settle, Cook Inlet Region, Inc.

The authors would also like to thank the following individuals from the National Renewable Energy Laboratory for their contributions. Helpful review and comments were provided by David Hurlbut, Jacquelin Cochran, Gian Porro, Bruno Grunau, Greg Brinkman, Doug Arent, and Meyer Seligman. Maps were generated by Billy Roberts. Editing was provided by Mike Meshek.

This work was authored by the National Renewable Energy Laboratory, operated by Alliance for Sustainable Energy, LLC, for the U.S. Department of Energy under Contract No. DE-AC3608GO28308. The views expressed in the article do not necessarily represent the views of the DOE or the U.S. Government. The U.S. Government retains a nonexclusive, paid-up, irrevocable, worldwide license to publish or reproduce the published form of this work, or allow others to do so, for U.S. Government purposes. 


\section{List of Acronyms and Abbreviations}

AC

AEA

BESS

CHP

$\mathrm{CC}$

$\mathrm{CT}$

DC

EIA

GVEA

GWh

HEA

HVDC

IC

MEA

MMBTU

MW

NREL

PM

PV

RPS

TWh alternating current

Alaska Energy Authority

battery energy storage system

combined heat and power

combined cycle

combustion turbine

direct current

U.S. Energy Information Administration

Golden Valley Electric Association

gigawatt-hours

Homer Electric Association

high-voltage direct current

internal combustion

Matanuska Energy Association

million British thermal units

megawatts

National Renewable Energy Laboratory

particulate matter

photovoltaics

renewable portfolio standard

terawatt-hours 


\section{Executive Summary}

In December 2021, the Governor of Alaska, Michael Dunleavy, requested support from the National Renewable Energy Laboratory (NREL) to perform a quick turnaround, preliminary analysis of the potential impacts of achieving an $80 \%$ renewable energy portfolio standard (RPS) on Alaska's Railbelt. The Railbelt runs north-south from Fairbanks through Anchorage to the Kenai Peninsula and represents $75 \%$ of Alaska's electric load. As it is not interconnected to a larger grid, and it is a winter peaking load, the Railbelt represents a unique electrical system in the United States.

Due to the quick turnaround time of approximately six weeks, we focused on (1) developing a set of plausible $80 \%$ RPS scenarios, (2) ensuring the envisioned $80 \%$ renewable energy systems could balance load in every hour of the year and provide sufficient operating reserve, and (3) confirming the dispatch resulted in an $80 \%$ renewable energy supply, along with quantifying fuel savings. Though this limited approach does not definitively identify the optimal RPS portfolio or provide a comprehensive cost analysis, it can provide insights into the basic techno-economic feasibility of an $80 \%$ RPS. It can also help identify some of the likely elements of such a portfolio, such as the potential need for new transmission and storage, and the opportunity to diversify the energy mix to increase resilience to fuel price volatility and reduce reliance on single fuels. This analysis is a starting point for additional research and consideration of investment or policy options. Other factors that can inform decision-making are not considered here.

The analysis includes development of a Base Case scenario that assumes no additional renewable deployments beyond the planned Bradley Lake Expansion - Dixon Diversion and 25 megawatts (MW) of small run-of-river hydropower. We then developed five $80 \%$ RPS scenarios with various mixes of renewable energy technologies including solar, wind, hydropower, geothermal, biomass, landfill gas, and tidal energy. The scenarios include one where hydropower provides about $65 \%$ of annual generation, and one where wind and solar combined provide about $60 \%$ of annual generation.

Each of the scenarios was simulated over a full year of system operation to ensure the demand for electricity could be met with the available resources, including under conditions of extended outages of major transmission lines and generation resources. There are two overall findings.

\section{Overall Finding 1: Multiple pathways exist for achieving an 80\% RPS while balancing supply and demand under major outage conditions with appropriate system engineering.}

The overarching finding of this analysis is that there are likely multiple pathways to achieving an $80 \%$ RPS while maintaining reliable service. All modeled scenarios can achieve $80 \%$ renewable energy while maintaining a balance of supply and demand with no unserved energy or reserve shortages during normal operations. The system can also serve load under severe outage conditions in all cases, although the $80 \%$ RPS may not be achieved if very long (weeks to months) outages were to occur on some parts of the grid. This finding depends on the continued use of best practices and the engineering approaches historically deployed by Alaska's Railbelt utilities, particularly regarding the use of state-of-the-art (commercially available) technologies. Reliable operation was achieved in the model by maintaining a portion of the existing fossil fleet, 
while leveraging the flexibility of hydropower, energy storage, and substantial upgrades to the Alaska Intertie.

\section{Overall Finding 2: An 80\% RPS achieves a substantial reduction in fuel costs, which could be compared to capital cost expenditures for a comprehensive impact assessment.}

Compared to the base case in 2040, an 80\% RPS would reduce Alaska's annual fossil fuel use by $25-31$ trillion BTU. ${ }^{1}$ Using a blended fuel price projection of $\$ 16.6 / \mathrm{MMBTU}$, this corresponds to an annual savings of $\$ 426$ to $\$ 506$ million. Associated benefits such as fuel price and customer rate stability, job creation and local air quality were not considered. This savings will need to be compared to the net change in annualized capital costs of investments in additional fossil and renewable resources, storage, and transmission needed for either a businessas-usual path or the $80 \%$ RPS. Important next steps could include a comprehensive analysis of costs and benefits (including resilience) of various scenarios, analysis to support the interim targets, and engineering analysis of required transmission system upgrades to support deployment of renewable energy technologies in various locations throughout Alaska's Railbelt grid.

This preliminary analysis was conducted to meet an immediate need and was based on the best information available within timing constraints. NREL used existing data available at the laboratory, information from the Governor's Office, as well as data from utilities, the Alaska Energy Authority, the Renewable Energy Alaska Project and others, where available. The preliminary analysis covers the service areas of five Alaska Railbelt utilities (alphabetically):

- Chugach Electric Association

- City of Seward Electric Department

- Golden Valley Electric Association

- Homer Electric Association

- Matanuska Electric Association.

This analysis only included technology options included in the draft RPS design that was provided to NREL by the Governor's office. These resources include biomass, geothermal, hydropower, landfill gas, solar PV, tidal energy, and wind.

\footnotetext{
${ }^{1}$ For context, this is the energy equivalent of about 4.3-5.3 million barrels of oil, although most of the energy saved will likely be in the form of natural gas.
} 


\section{Table of Contents}

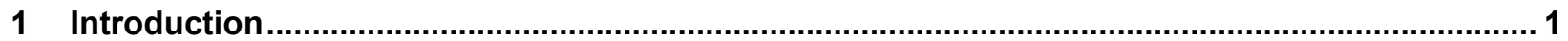

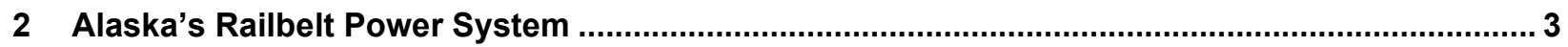

3 Opportunities for Renewable Electricity in Alaska ............................................................... 8

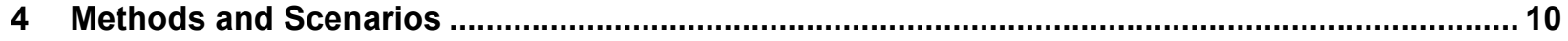

4.1 Study Approach............................................................................................... 10

4.2 Base Case 2040 Case: No New Renewable Energy ....................................................... 13

$4.380 \%$ RPS Scenarios .......................................................................................... 15

4.4 Iterative Additions to Provide Resource Adequacy Under Normal and Outage Scenarios ........ 17

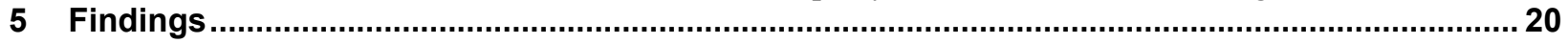

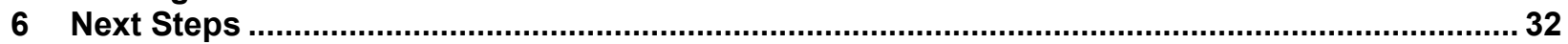

Appendix A. Resource Maps for Alaska's Railbelt .................................................................... 33

Appendix B. Performance and Deployment Opportunities by Region along the Alaska Railbelt.... 39

Appendix C. Supplemental Information................................................................................4 


\section{List of Figures}

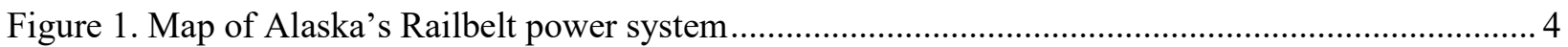

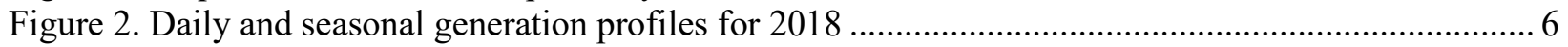

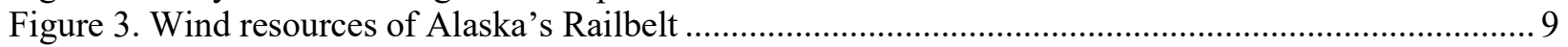

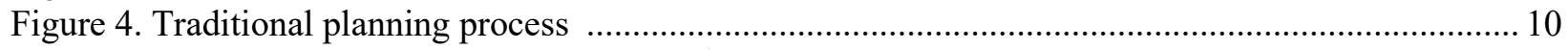

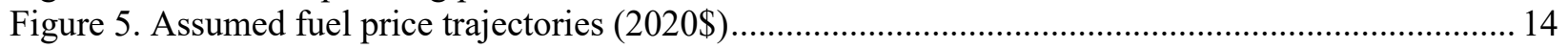

Figure 6. Stacked bar charts of sources of generation during three hours for the six scenarios ................ 21

Figure 7. System dispatch on the peak demand day in Scenarios 1 (top) and 3 (bottom) ....................... 22

Figure 8. The impact of wind and solar on net load during a four-day period in January ......................... 23

Figure 9. Operation of the Bradley Lake hydroelectric plant ............................................................ 24

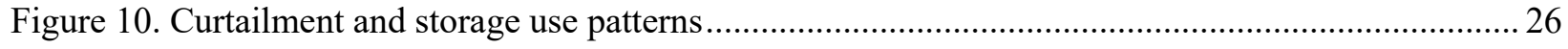

Figure 11. Fraction of demand met by wind and solar in the first two months of the year in Scenario 3 .. 27

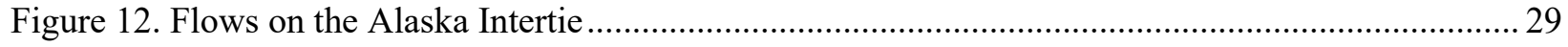

Figure 13. Annual fossil generation in 2040 by region..................................................................... 30

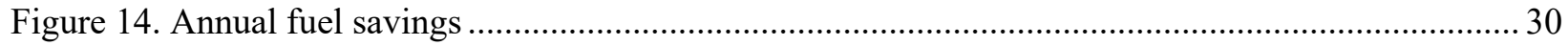

Figure 15. Conceptual illustration of analysis needed to identify impact on total system costs.................31

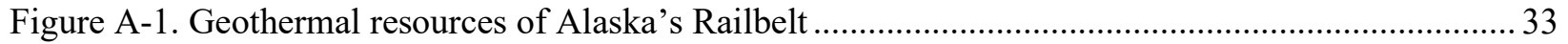

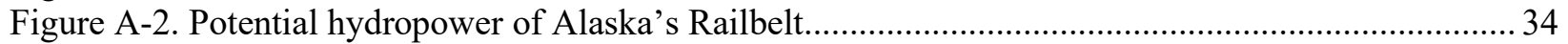

Figure A-3. Potential pumped storage hydropower of Alaska's Railbelt ................................................ 35

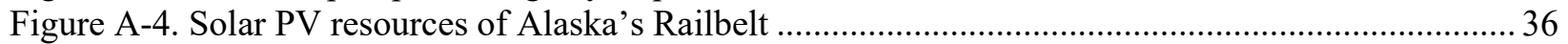

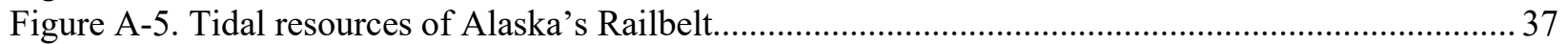

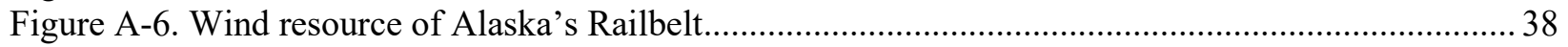

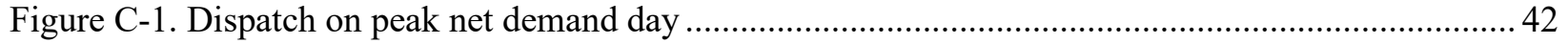

\section{List of Tables}

Table 1. Characteristics of Alaska's Railbelt Utilities ............................................................................ 3

Table 2. Generation Resource Types for the Utilities in Alaska's Railbelt (2020 Data) ........................... 7

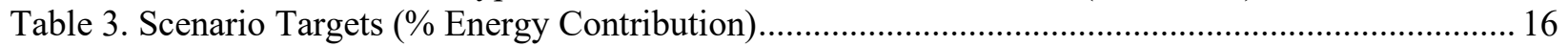

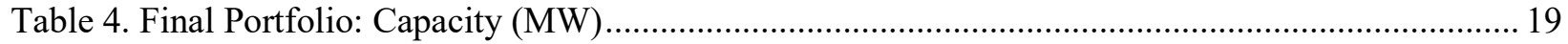

\section{List of Text Boxes}

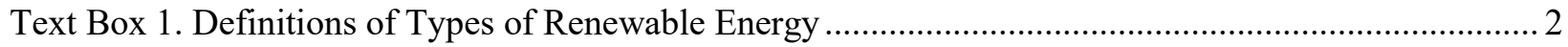

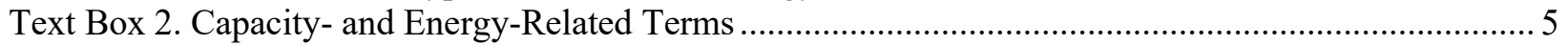

Text Box 3. Key Performance Indicators: The Three Rs....................................................................... 12 


\section{Introduction}

As of 2020, 30 states had enacted a renewable portfolio standard (RPS), which requires states' utilities to derive a certain fraction of their total electricity generation from renewable resources. This report evaluates an $80 \%$ RPS, where $80 \%$ is defined as the fraction of electricity generated in Alaska's Railbelt grid. Based on the current draft RPS design in Alaska, six technologies were considered: hydropower, solar, wind, tidal energy, geothermal, biomass (including landfill gas). ${ }^{2}$ The requirement applies to the Railbelt as a whole, which implies renewable energy certificate (REC) trading between individual utilities, but not beyond the Railbelt or to other states. We assume full compliance, and therefore do not consider compliance penalties or other policy components such as credit banking. ${ }^{3}$ The target date for $80 \%$ is 2040 , and while the draft proposal includes interim targets, these were not evaluated due to the short project timeline.

In lieu of a more comprehensive analysis required for a full planning study, due to the quick turnaround time, we focused on (1) developing a set of plausible $80 \%$ RPS scenarios, (2) ensuring the envisioned $80 \%$ renewable energy systems could balance load in every hour of the year and provide sufficient operating reserve, and (3) confirming the dispatch resulted in $80 \%$ renewable energy supply, along with quantifying fuel savings. Section 4 of this report itemizes the other elements needed for a detailed resource plan.

Each renewable type that is included in the current draft RPS design is defined in Text Box 1.

The draft RPS focuses primarily on the 2040 goal of $80 \%$ - rather than lower interim goalsbecause of time constraints. And the study aims to provide:

- A preliminary feasibility analysis of an $80 \%$ RPS, considering possible mixes of resources that could meet this goal, and a discussion of the elements needed to ensure reliable operation

- A discussion of possible cost impacts, including the further analysis needed to provide a more comprehensive estimate of the costs and benefits of achieving a goal of $80 \%$ renewable electricity.

The report includes five additional sections:

- General information about Alaska's Railbelt power system (Section 2)

- Opportunities for renewable energy along Alaska's Railbelt (Section 3)

- Our model approach, methodology, and scenario assumptions (Section 4)

- Findings from the model (Section 5)

- Potential Next steps (Section 6)

\footnotetext{
${ }^{2}$ Eligible technologies vary by state and region, and often include other approaches, such as energy efficiency, or renewably derived fuels such as hydrogen.

${ }^{3}$ For addition discussion of RPS design and features see "Renewable Portfolio Standards," NREL, https://www.nrel.gov/state-local-tribal/basics-portfolio-standards.html.
} 
Note that this analysis was conducted to meet an immediate need and was based on the best information available within timing constraints. It is a starting point for additional research and consideration of investment or policy options. Other factors that can inform decision-making are not considered here. The analysis results are not intended to be the sole basis of investment, policy, or regulatory decisions but are rather intended to understand the technical viability of an $80 \%$ RPS.

\section{Text Box 1. Definitions of Types of Renewable Energy}

Solar Energy-where energy from the sun is collected for heat to convert it to electricity. For the purposes of this study, solar energy is assumed be attained using photovoltaic (PV) technology. A PV cell, or a solar cell, converts sunlight directly into electricity

Wind Energy - where kinetic energy from wind is collected using wind blades, where wind flows over the blades creating lift, causing the blades to turn. The wind blades are connected to a drive shaft that turns an electric generator to produce electricity.

Hydropower-where kinetic energy from moving water flows through a penstock and then pushes against and turns blades in a turbine to spin a generator to produce electricity. Conventional hydropower facilities are typically either (1) run-of-river facilities where the force of the river's current applies pressure on a turbine or (2) storage facilities where water accumulates in reservoirs created by dams on streams and rivers and is released through turbines to generate electricity.

Biomass - where stored chemical energy from the sun found in organic materials is burned directly for heat or converted to renewable liquid and gaseous fuels through various processes. Biomass sources for energy include wood, wood processing wastes, agricultural crops and waste materials, biogenic materials in municipal solid waste and animal manure, and human sewage For purposes of this study, this energy source is attained by wood, crops, and landfill materials.

Geothermal-where heat from the Earth is extracted and used for heating and to produce electricity. Geothermal power plants use both water and heat. This resource is accessed by drilling wells and piping steam or hot water to the surface, which, in turn powers a turbine that generates electricity.

Tidal - where kinetic energy from the rise and fall of ocean tides is converted to power, mainly electricity using a generator. Tides are cyclical and predictable as they are created by the gravitational effects of the moon and the sun on the Earth

Source: "Energy Explained: Your Guide to Understanding Energy," EIA, https://www.eia.gov/energyexplained/. 


\section{Alaska's Railbelt Power System}

This analysis applies to Alaska's Railbelt power system, which extends from Fairbanks through Anchorage to the Kenai Peninsula and consists of four electric cooperatives and one municipally owned (not-for-profit) utility that serve about $75 \%$ of Alaska's electricity (Table 1 ).

Table 1. Characteristics of Alaska's Railbelt Utilities

Data are for 2020 and from U.S. Energy Information Administration (EIA) Form 861. a

\begin{tabular}{|l|c|c|c|}
\hline Utility & $\begin{array}{c}\text { Annual Sales } \\
\text { (GWh) }\end{array}$ & $\begin{array}{c}\text { Customers } \\
\text { (thousands) }\end{array}$ & $\begin{array}{c}\text { Fraction of Railbelt } \\
\text { Annual Demand (\%) }\end{array}$ \\
\hline Chugach Electric Association $^{\mathrm{b}}$ & 1,945 & 144 & 44 \\
\hline Golden Valley Electric Association & 1,222 & 47 & 28 \\
\hline Matanuska Electric Association & 751 & 67 & 17 \\
\hline Homer Electric Association & 437 & 33 & 10 \\
\hline City of Seward Electric Department & 52 & 3 & 1 \\
\hline Total & $\mathbf{4 , 4 0 8}$ & $\mathbf{2 9 3}$ & $\mathbf{1 0 0}$ \\
\hline
\end{tabular}

a "Annual Electric Power Industry Report, Form EIA-861 detailed data files," EIA, https://www.eia.gov/electricity/data/eia861/

${ }^{\mathrm{b}}$ Combines data from the Chugach Electric Association and Anchorage Municipal Light \& Power which merged in late 2020.

Figure 1 illustrates Alaska's Railbelt region. Fairbanks is served by the Golden Valley Electric Association (GVEA). For the purposes of modeling, we combined the Chugach Electric Association (serving Anchorage), the Matanuska Energy Association (MEA), and the City of Seward Electric Department (City of Seward) into a single zone we labeled Central as discussed in Section 3. The Homer Electric Association (HEA) serves the Kenai Peninsula. 


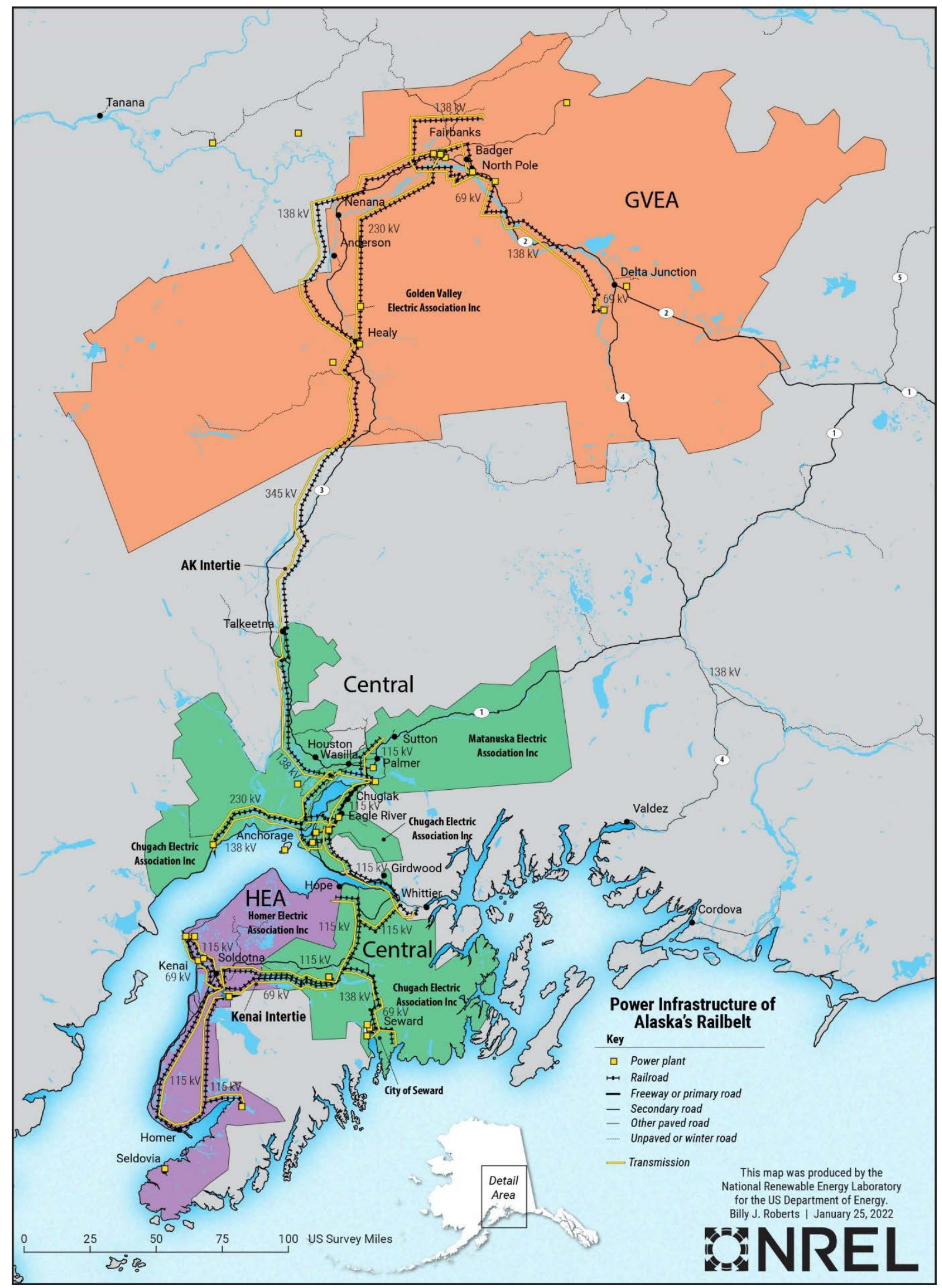

Figure 1. Map of Alaska's Railbelt power system 
The demand for electricity in each of these regions varies as a function of time of day and season. Figure 2(a) shows daily load profiles in 2018 for the Central Region (combining Chugach Electric Association, MEA and Seward), GVEA, and HEA in the 4-day period with highest (system-wide) annual demand, which occurred during the hour ending 7 p.m. on January 25. Figure 2(b) shows the total system-wide demand for this period, as well as for the periods with the lowest demand in October and the highest summer demand in July. ${ }^{4}$ For clarification, Text Box 2 defines capacity versus energy. The Railbelt system is winter-peaking, which is different from most of the contiguous United States.

\section{Text Box 2. Capacity- and Energy-Related Terms}

Capacity (also "nameplate capacity" or "peak capacity") generally refers to the rated output of a power plant when operating at maximum output. The capacity of individual power plants is typically measured in kilowatts (kW) or megawatts (MW). The cumulative capacity of systems is often measured in gigawatts (GW) or terawatts (TW). Capacity of power plants is typically measured by their net $A C$ rating, and we use this standard in this report.

Energy, in this report, refers to electricity generated and used for lighting, appliances, etc. It is typically measured in kilowatt-hours (kWh) and represents one kW of power used for an hour.

Capacity factor (\%) is a measure of how much energy is produced by a plant compared to its maximum output. It is calculated by dividing the total energy produced during some period of time by the amount of energy it would have produced if it ran at full output over that period of time.

Capacity credit is a measure of the contribution of a power plant to resource adequacy, meaning the ability of a system to reliably meet demand during all hours of the year. It is measured either in terms of capacity $(\mathrm{kW}, \mathrm{MW})$ or the fraction of its nameplate capacity (\%) and indicates the amount or portion of the nameplate capacity that is reliably available to meet load during times of highest system demand-typically the highest net-load hours of the year.

\footnotetext{
${ }^{4}$ Note that the terms generation, load, and demand throughout this document refer to the generation required to serve the end-use demand, plus transmission losses and internal use. Therefore, numbers will generally be about $7 \%$ higher on average when compared to actual sales to end customers. This reflects transmission and distribution losses.
} 


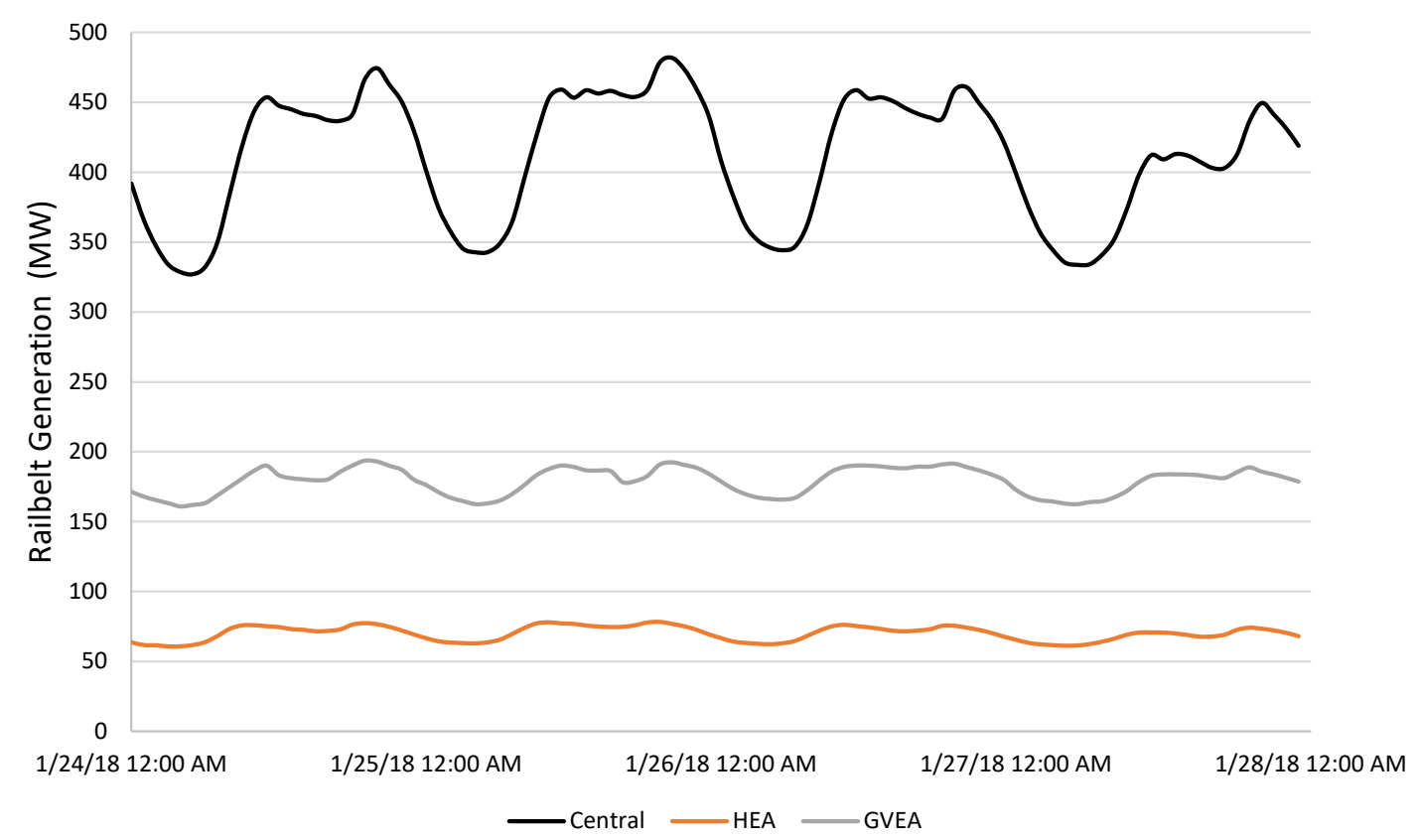

Winter peak generation for three modeled utility regions: Central, GVEA, and HEA

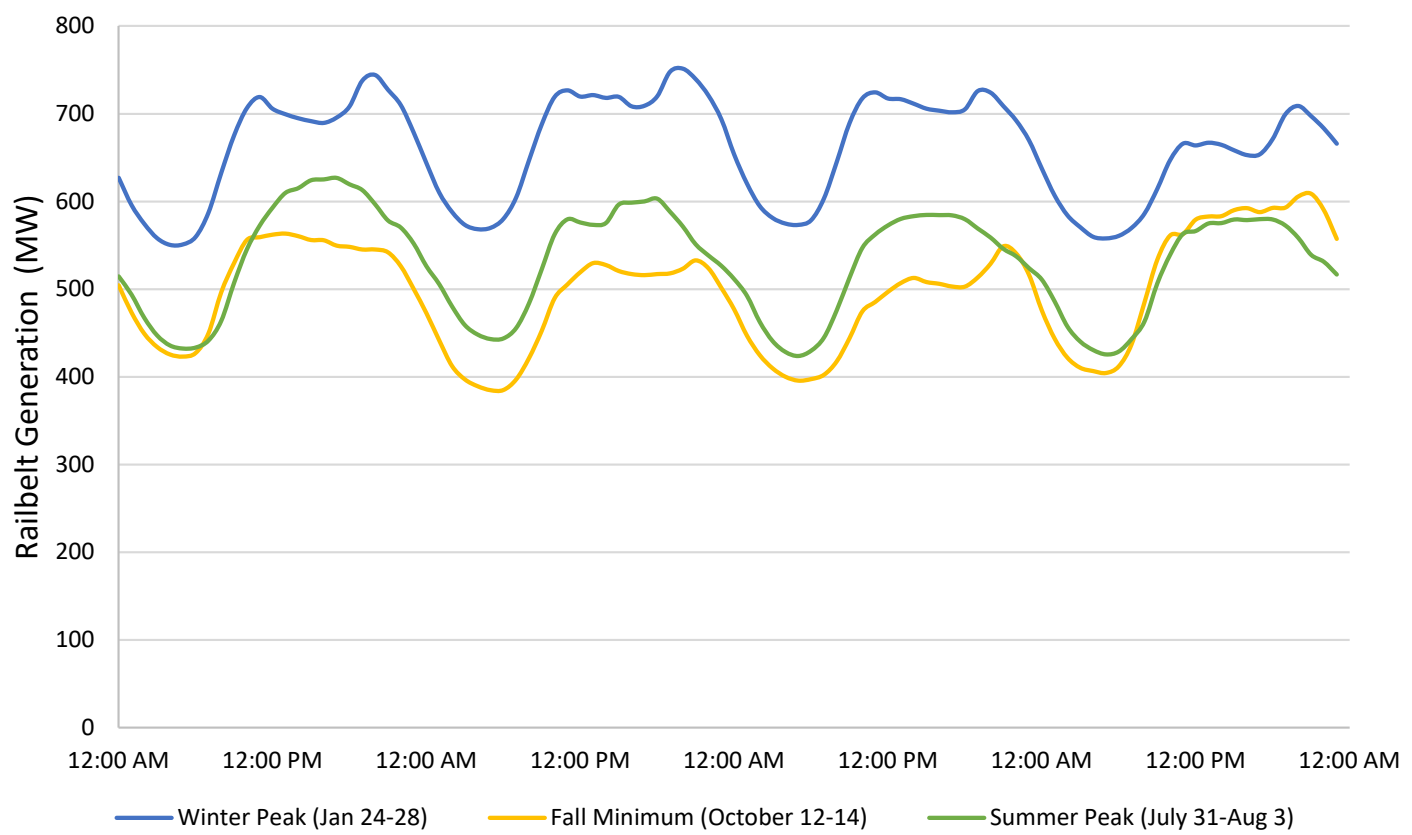

(b) Total generation in three periods in Alaska's Railbelt

Figure 2. Daily and seasonal generation profiles for 2018

All five utilities are electrically interconnected, which allows the utilities to exchange resources and thus improve the economic operation of the grid. However, the connection between GVEA and the utilities to the south via the Alaska Intertie is limited; also limited are the connections to HEA through the Kenai Intertie (see Figure 1, for the location of these interties). Because transmission outages can occur, these regions can operate largely independently. 
Because of the need for utilities to operate reliably during failures of these interties, as well as their relatively small size (which limits the diversity of resources), each utility carries a significant reserve margin (total capacity compared to peak load). Table 2 summarizes the system-wide capacity and generation mix in 2020 . The combined system capacity of about 1,826 MW, is about 1,075 MW higher than the 2018 peak demand of $751 \mathrm{MW}$, which equates to a reserve margin of about 143\%. For comparison, North American Electric Reliability Corporation-recommended reserve margins for (larger and more interconnected) utilities in the lower 48 states are $13 \%-17 \% .^{5}$

Table 2. Generation Resource Types for the Utilities in Alaska's Railbelt (2020 Data) ${ }^{6}$

\begin{tabular}{|c|c|c|c|}
\hline Generator Type & $\begin{array}{l}\text { Capacity }{ }^{a} \\
\text { (MW) }\end{array}$ & $\begin{array}{c}\text { Generation } \\
\text { (GWh) }\end{array}$ & $\begin{array}{c}\text { Generation } \\
\text { Fraction }\end{array}$ \\
\hline Gas/oil combustion turbine (CT) & 754 & 632 & $14 \%$ \\
\hline Gas/oil internal combustion (IC) & 193 & 732 & $16 \%$ \\
\hline Gas/oil combined cycle (CC) & 561 & 1,676 & $36 \%$ \\
\hline Coal & 75 & 348 & $8 \%$ \\
\hline Unspecified fossil purchases ${ }^{b}$ & $\mathrm{n} / \mathrm{a}$ & 310 & $7 \%$ \\
\hline Fossil Subtotal & 1,585 & 3,698 & $80 \%$ \\
\hline Hydropower & 190 & 815 & $18 \%$ \\
\hline Wind & 44 & 97 & $2 \%$ \\
\hline Landfill gas & 7 & 39 & $1 \%$ \\
\hline Solar & 1 & 1 & $<1 \%$ \\
\hline Renewable Subtotal & 241 & 951 & $20 \%$ \\
\hline Total $^{c}$ & 1,826 & 4,649 & $100 \%$ \\
\hline
\end{tabular}

a This does not include the $147 \mathrm{MW}$ of combined heat and power plants in the Railbelt system reported on EIA 861. These units generated about $444 \mathrm{GWh}$ in 2020. Much of this electricity was used on site. However, some of this was sold to utilities and accounts for some of the unspecified energy.

$\mathrm{b}$ This value was estimated based on estimated total generation (see note $\mathrm{c}$ ) minus the total generation accounted for in Form EIA-923.

c This value was estimated based on the total generation required for retail sales plus losses reported in in Form EIA861.

Overall, the system obtained about $80 \%$ of its electricity from fossil resources in 2020 , and about $20 \%$ from renewables with the majority derived from hydropower. ${ }^{7}$

\footnotetext{
5 Andrew Reimers, Wesley Cole, and Bethan Frew, "The Impact of Planning Reserve Margins in Long-Term Planning Models of the Electricity Sector," Energy Policy 125: 1-8, 2019, https://doi.org/10.1016/j.enpol.2018.10.025.

${ }^{6}$ Data from Form EIA-861 and Form EIA-923 for the year 2020.

${ }^{7}$ The load in 2020 was lower than in some previous years, with good hydropower production, which increased the relative contribution from renewable resources.
} 


\section{Opportunities for Renewable Electricity in Alaska}

Renewable energy provides several advantages as a source of electricity. Deployment of renewable energy provides increased price stability in markets that have historically been subject to significant fuel price variability, as costs are dominated by capital investments and most have no fuel costs. In addition, some renewable energy resources have lower life-cycle costs than fossil fuel-generated electricity. According to a comprehensive cost study conducted by the International Renewable Energy Agency in 2020 which analyzes renewable energy project cost and auction price data from projects around the globe, renewable power generation costs have continued to decline coupled with improvements in many areas including, but not limited to, technologies, economies of scale, supply chain competition, and more. ${ }^{8}$ The Land-Based Wind Market Report, ${ }^{9}$ an annual report provided by the Lawrence Berkeley National Laboratory (LBNL), states that "low power purchase agreement prices have been facilitated by the combination of higher capacity factors, declining installed costs and operating costs, and low interest rates." A similar 2021 technical brief by LBNL on utility-scale solar ${ }^{10}$ states that median installed project costs have steadily fallen at an average of $12 \%$ annually since 2010 . Other benefits of renewable energy include local jobs and economic development, as well as improved local air quality, which is a major concern in several areas of Alaska's Railbelt that are at, or are nearing, non-attainment status for fine particulate matter $\left(\mathrm{PM}_{2.5}\right) \cdot{ }^{11}$ A renewable portfolio also allows for a reduction in risk associated with carbon pricing or regulations and affords the Alaskan Railbelt a higher degree of energy independence.

Figure 3 is a map of the wind resource along Alaska's Railbelt, shown along an annual average wind speed gradient. The map, which also shows locations of existing wind energy plants, is illustrative of what can be found on the resource maps for solar, hydropower, pumped storage hydropower, geothermal, and tidal energy; see Appendix A for all these maps.

Performance and deployment opportunities for each Alaska Railbelt region are included in Appendix B.

Study methods and possible renewable energy scenarios to meet an $80 \%$ RPS are provided in the next section.

\footnotetext{
${ }^{8}$ IRENA (International Renewable Energy Agency). 2021. Renewable Power Generation Costs in 2020, International Renewable Energy Agency, Abu Dhabi.

${ }^{9}$ Ryan Wiser, Bolinger, Mark Bolinger, Ben Hoen, Dev Millstein, Joe Rand, Galen Barbose, Naïm Darghouth, et al., 2021. Land-Based Wind Market Report: 2021 Edition. U.S. Department of Energy Office of Energy Efficiency and Renewable Energy. DOE/GO-102021-5611. https://www.energy.gov/sites/default/files/202108/Land-Based\%20Wind\%20Market\%20Report\%202021\%20Edition_Full\%20Report_FINAL.pdf.

${ }^{10}$ Mark Bolinger, Joachim Seel, Cody Warner, and Dana Robson. 2021. Utility-Scale Solar, 2021 Edition. https://emp.lbl.gov/sites/default/files/utility-scale solar_2021 technical brief.pdf

${ }^{11}$ State of Alaska Department of Transportation \& Public Facilities, 2020-2023 Statewide Transportation Improvement Program (STIP), Approved November 23, 2021, Amendment 3 and Incorporated Administrative Modifications (State of Alaska Department of Transportation and Public Facilities, 2021), https://dot.alaska.gov/stwdplng/cip/stip/assets/STIP.pdf.
} 


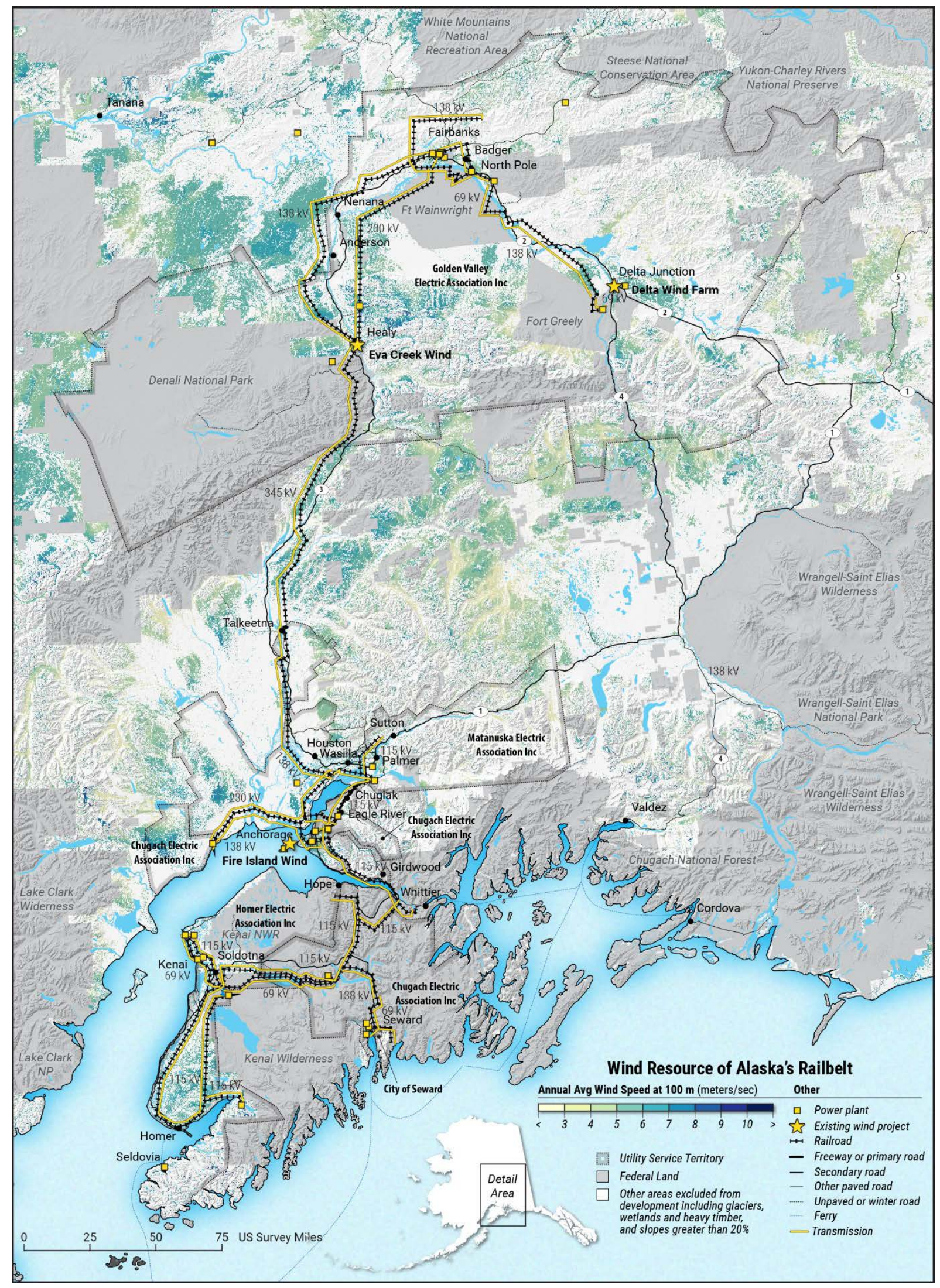

Figure 3. Wind resources of Alaska's Railbelt 


\section{Methods and Scenarios}

In a standard planning study, scenarios are developed and analyzed using a multistep process like the one outlined in Figure 4. The process includes the generation of detailed load forecasts and distributed resource adoption scenarios, followed by the use of a capacity expansion model to develop an optimized portfolio that produces a mix of resources with the lowest life-cycle cost. These scenarios are then analyzed with multiple tools to ensure (1) reliable operation of the generation and transmissions system and (2) sufficient generation is available to meet demand under all conditions, including immediately after failures of generation and transmission equipment. The quick turnaround for this work limited our standard utility planning study approach to a subset as described below.

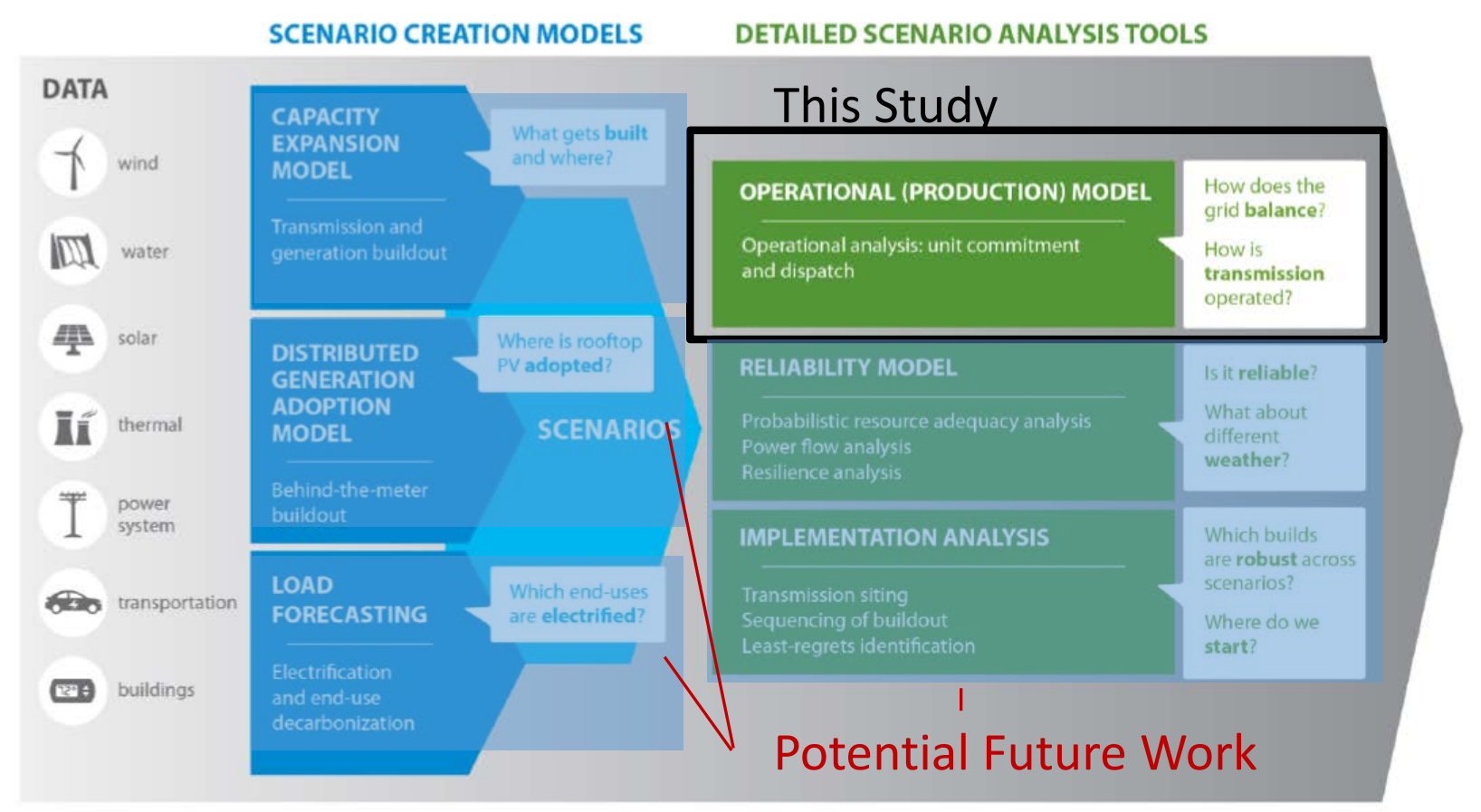

Figure 4. Traditional planning process ${ }^{12}$

\subsection{Study Approach}

In lieu of a more comprehensive analysis required for a full planning study, we focused on (1) developing a set of plausible $80 \%$ RPS scenarios, (2) ensuring the envisioned $80 \%$ renewable energy systems could balance load in every hour of the year and provide sufficient operating reserve, and (3) confirming the dispatch resulted in $80 \%$ renewable energy supply, along with quantifying fuel savings.

\footnotetext{
${ }^{12}$ Gregory Brinkman, Dominique Bain, Grant Buster, Caroline Draxl, Paritosh Das, Jonathan Ho, Eduardo Ibanez, et al. 2021. The North American Renewable Integration Study: A U.S. Perspective-Executive Summary. Golden, CO: National Renewable Energy Laboratory. NREL/TP-6A20-79224-ES.

https://www.nrel.gov/docs/fy21osti/79224-ES.pdf.
} 
Though this limited approach does not definitively identify the optimal RPS portfolio or provide a comprehensive cost analysis, it can provide insights into the basic techno-economic feasibility of an $80 \%$ RPS, and it can help identify some of the likely elements of such a portfolio, such as the potential need for new transmission and storage, and the role of a diverse mix of new resources.

To perform the analysis, we first developed a set of five $80 \%$ renewable energy scenarios, exploring a range of portfolios that emphasize different technology options. We then evaluated those scenarios using the PLEXOS production cost model, which is a commercial tool used by utilities and system operators in the United States. ${ }^{13}$ Production cost models simulate the hourly operation of the generation and transmission system by turning on and off generators and varying their output to ensure the demand for electricity is met while minimizing system operating cost. ${ }^{14}$ These models also optimize the use of storage to balance supply and demand, and they consider how the system will maintain sufficient operating reserve to address the inherent variability and uncertainty of both supply and demand, including events such as sudden outages of generators or transmission and the inability to perfectly forecast the supply of renewable resources. The carrying capacity of the transmission network is also considered and can be used to demonstrate the value of transmission upgrades in key regions.

This type of simulation is an iterative process. Initial scenarios may prove infeasible, meaning the demand for electricity is not always served in all regions. In these cases, the portfolio can be adjusted, and simulations can be repeated until a reliable mix of resources is identified. Text Box 3 introduces the elements of power system reliability and those considered in this work.

\footnotetext{
${ }^{13}$ For an example study using this tool, see "Interconnections Seam Study," NREL, https://www.nrel.gov/analysis/seams.html. Additional model details are available at "PLEXOS," Energy Exemplar, https://www.energyexemplar.com/plexos.

${ }^{14}$ NREL often evaluates subhourly variability, but insufficient data were available to consider the impact of increased subhourly variability in this study; instead, we used conservative estimates for operating reserve requirements needed to address ramp rate requirements within the hour.
} 


\section{Text Box 3. Key Performance Indicators: The Three Rs}

The primary focus of this work was to develop and evaluate $80 \%$ RPS portfolios that reliably serve customer demand, or more simply stated, keep the lights on. While this goal is often expressed as "reliability," it is important to note that reliability involves elements that can be summarized in terms of the three Rs: resource adequacy, operational reliability, and resilience.

Resource adequacy represents planning for the system's ability to supply enough electricity-at the right locations - to keep the lights on, even during extreme weather days and when reasonable outages occur. An adequate system has sufficient spare capacity to replace capacity that fails or is out of service for maintenance. Increasingly, resource adequacy must account for the variability of renewable energy supply, the role of storage, and changes in demand patterns. We directly evaluated resource adequacy was in this study by calculating the reserve capacity available during peak demand conditions and under transmission outage condition.

Operational reliability enables a system to operate in the seconds during an abnormal event and minutes after an event. It includes operating reserve and frequency stability, including inertia. Maintaining operational reliability with growth in inverter-based resources is an important element of the power sector transition. We considered operational reliability in this study by maintaining adequate operating reserve that could respond with the necessary speed; however, we did not directly simulate actual events, such as contingencies are; doing so would require a separate, dedicated analysis. For this study, we assumed continued growth in the use of fast-responding inverters-based resources including batteries, which have been used in this role in Alaska for over a decade.

Resilience represents a power system's ability to withstand and reduce the impact of disruptive events. Resilience overlaps with the other aspects of reliability; however, one unique aspect of resilience is related to system recovery-or how quickly power can be restored after an outage. In this study, we considered resource adequacy and operational reliability by maintaining adequate capacity (including weather variability) and operating reserve; however, we did not directly measure resilience. 


\subsection{Base Case 2040 Case: No New Renewable Energy}

The study began with the development of a power system model of the existing Alaska Railbelt system that could be used as a reference case (Base case), and this was followed by the development and evaluation of various $80 \%$ portfolios. This Base case system for 2040 assumed no additional deployment of renewable energy other than $25 \mathrm{MW}$ of small run-of-river hydropower in the southcentral region and the Bradley Lake Expansion - Dixon Diversion which we have been informed is in advanced planning stages. Note that there are two Bradley Lake Expansion-Dixon Diversion options. Both include a diversion of Dixon Glacier runoff and a dam raise at Bradley Lake, but only the second option considers an additional 63-MW turbine at the Bradley Lake power station. A third option involves an additional run-of-river power plant at Martin River, but detailed reports on this option are ongoing so we did not consider it in our scenarios.

\section{Regional Load}

The demand in 2040 was based on the hourly load profiles obtained for each utility for 2018 . This year was chosen in part because it corresponds to the availability of simulated wind resource data and because it occurred before the impacts of the COVID-19 pandemic on electricity demand. To account for load growth, these demand profiles were scaled to projected 2040 demand based on population growth estimates. ${ }^{15}$ However, we did not consider changes in load shape resulting from electric vehicle adoption, electrification of heating through heat pump technologies, other electrification, or changing weather patterns. This scaling resulted in a 2040 annual generation of 5.2 TWh (about a 12\% increase compared to 2020) ${ }^{16}$ and a peak generation of $820 \mathrm{MW}$.

\section{Generation Fleet}

We started with each utilities' existing generation fleet, using capacity and performance based on utility-provided data and supplemented with public sources. ${ }^{17}$ By 2040 , many of the thermal resources will be older than their expected lifetimes, so we retired all thermal units at the age of approximately 60 years based on historical averages. ${ }^{18}$ This resulted in retirements of $427 \mathrm{MW}$ of capacity. ${ }^{19}$ Because of these retirements and load growth, we added fossil capacity to the generation fleet to the Base Case to meet the reliability criteria discussed in Section 4.4.

\footnotetext{
15 State of Alaska Department of Labor, 2022, “Alaska Population Projections 2019 to 2045." https://live.laborstats.alaska.gov/pop/projections.html.

${ }^{16}$ Compared to data from EIA-860.

17 "Form EIA-860 Detailed Data with Previous Form Data (EIA-860A/860B)," EIA, https://www.eia.gov/electricity/data/eia860/.

"Form EIA-923 Detailed Data with Previous Form Data (EIA-906/920)," EIA, https://www.eia.gov/electricity/data/eia923/.

${ }_{18}$ Andrew Mills, Ryan Wiser, Joachim Seel. 2017. Power Plant Retirements: Trends and Possible Drivers. Lawrence Berkeley National Laboratory. https://etapublications.lbl.gov/sites/default/files/lbnl_retirements_data_synthesis_final.pdf.

19 The larger retirements we assume include Beluga units 1,3, and 5, Healy units 1 and 2, George Sullivan Plant 2 unit 7, Hank Nikkels unit 3, Delta Power, Bernice Lake unit 1, and Chena units 1,2, and 3.
} 
We also added the Bradley Lake dam raise-Dixon Diversion which is expected to provide about 150 annual GWh. We considered a third $63 \mathrm{MW}$ turbine at the Bradley Lake power station in most of our $80 \%$ scenarios, but not the base case.

\section{Fuel Prices}

Fuel prices trajectories were derived from projections by the Alaska Energy Authority (Figure 5).

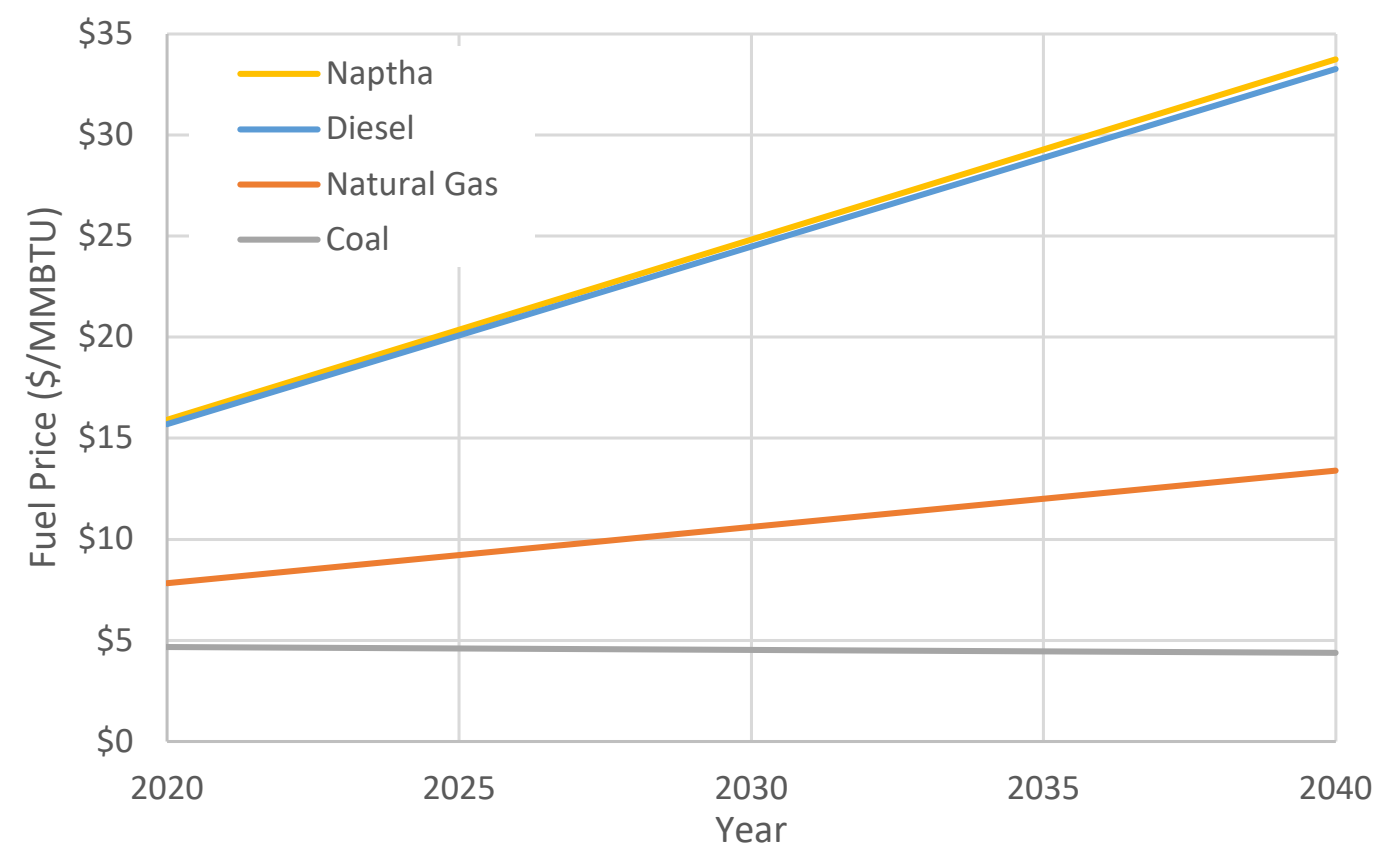

Figure 5. Assumed fuel price trajectories (2020\$)

\section{Transmission}

Our model aggregated Alaska's Railbelt power system into three transmission zones illustrated in see Figure 1, page 4. Transmission within each modeled zone was unconstrained. Between each zone, the system model used a limited representation of the current transmission networkevaluating only the major paths (this assumption applies to both the base case and all $80 \%$ scenarios):

- Alaska Intertie: Runs from Healy to Teeland and is currently rated at about $78 \mathrm{MW}$ of capacity. We assume that by 2040 it is upgraded to $250 \mathrm{MW}$ and we perform supplemental analysis where it is increased to over $300 \mathrm{MW}$ of capacity. ${ }^{20}$

- Kenai Intertie: Runs from Soldotna to Quartz Creek and is currently rated at about 75 MW of capacity. We assume upgrades to $100 \mathrm{MW}$ of capacity by 2040 .

No other existing or potential transmission constraints were considered, except where new renewable capacity was added in the $80 \%$ scenarios. In those cases, we assumed interconnections were sufficient to meet the full output of the new resource into the nearest/appropriate transmission zone or intertie. Only steady-state thermal limits were evaluated, but dynamics,

\footnotetext{
${ }^{20}$ These values are based on several Alaska transmission studies and correspondence with several utilities.
} 
including detailed stability and contingency analysis, were beyond scope of this preliminary analysis in the time allowed. We assumed average historical transmission and distribution loss rates which are embedded in the total generation profiles and did not consider how these rates might vary across the different scenarios.

\section{System Operation and Operating Reserve}

The system was simulated assuming system-wide economic unit commitment and dispatch, ${ }^{21}$ which essentially resulted in frictionless transactions between utility regions to maximize the economic and technical efficiency of the power grid. This study did not assume any specific regulatory approach that might achieve this type of operation. However, multiple approaches could be taken, including a consolidated balancing area authority or system operator or marketbased approaches. None of these approaches require utilities to merge or otherwise lose independence to ensure local reliability and rate setting.

We enforced two types of operating reserve. First, the system was assumed to maintain primary fast responding contingency reserves capable of preventing an under-frequency load shedding event after the sudden loss of the largest generation or transmission component. We also maintained a rapid-response regulating reserve, equal to $2 \%$ of load, to address short-term uncertainty. ${ }^{22}$

Once this baseline scenario was established, we evaluated it for reliability and further adjusted the portfolio as described in Section 4.4.

\section{$4.380 \%$ RPS Scenarios}

We created five RPS scenarios, each with sufficient generation capacity to meet $80 \%$ of annual generation after considering the deliverability of each renewable resource due to transmission congestion, losses in storage, and curtailment due to oversupply during periods of high renewable energy output or low electricity demand. We describe these scenarios briefly in this section and note that they are not intended to represent definitive or even likely mixes - rather, they showcase an array of possible pathways.

- Scenario 1: This scenario represents a case where significant new hydropower is developed. It assumes the characteristics and location of Susitna-Watana to represent this new resource. In addition, the Dixon Diversion project was added. This includes a dam raise at Bradley Lake to increase the annual energy budget by $150 \mathrm{GWh}$, as well as an additional $63 \mathrm{MW}$ turbine to fill the empty third bay at the existing Bradley Lake power station. Limited deployment of new wind and solar is required in this scenario.

- Scenario 2: This scenario also assumes significant hydropower development (but less than Scenario 1). It drops Susitna-Watana but keeps the aforementioned Dixon Diversion project and adds the proposed Grant Lake and Snow River hydropower projects. The net loss in hydropower production is replaced with wind and solar.

\footnotetext{
${ }^{21}$ A comprehensive analysis requires running a multistage unit commitment and economic dispatch which helps account for forecast errors. These data were unavailable; however, the high degree of flexibility in the Alaska system reduces the importance of modeling day-ahead unit commitment.

${ }^{22}$ We would typically perform an estimate of dynamic operating reserve requirements that account for the variability of wind and solar. Project timeline constraints prevented this, so we used a fixed level.
} 
- Scenario 3: This scenario further reduces hydropower production compared to scenario 2 by adding only the Dixon Diversion project and not Grant Lake or Snow River. Additional wind and solar is added to make up for the loss in hydropower production.

- Scenario 4: This scenario assumes the same hydropower development as Scenario 3 but removes some of the wind and solar and replaces it with tidal and geothermal energy.

- Scenario 5: This scenario represents the lowest hydropower development, which is the same as the Base Case. The only new, large hydropower project is the Bradley Lake dam raise, which increases its annual energy budget by $150 \mathrm{GWh}$. A third turbine is not included in this scenario. Additional tidal and geothermal are also assumed.

All scenarios except Scenario 1 also add $25 \mathrm{MW}$ of small run-of-river hydro in the Central region, and all scenarios include a $46 \mathrm{MW}$, 8-hour battery in GVEA, a 46.5 MW 4-hour battery in Homer, and a $70 \mathrm{MW}$ 4-hour battery in Central. Finally, all scenarios upgrade the thermal limits of the AK Intertie and Kenai Intertie to $250 \mathrm{MW}$ and $100 \mathrm{MW}$, respectively (same as the Base Case).

Table 3 summarizes the targets for the Base case (no new renewable energy) and five 80\% RPS scenarios.

Table 3. Scenario Targets (\% Energy Contribution)

\begin{tabular}{|l|c|c|c|c|c|c|}
\hline $\begin{array}{l}\text { Technology } \\
\text { (includes new and } \\
\text { existing) }\end{array}$ & $\begin{array}{l}\text { Base } \\
\text { Case }\end{array}$ & Scenario 1 & Scenario 2 & Scenario 3 & Scenario 4 & Scenario 5 \\
\hline Wind & $0 \%$ & $12 \%$ & $48 \%$ & $48 \%$ & $49 \%$ & $45 \%$ \\
\hline Solar & $0 \%$ & $1 \%$ & $7 \%$ & $12 \%$ & $4 \%$ & $3 \%$ \\
\hline $\begin{array}{l}\text { Hydropower } \\
\text { (conventional dam } \\
\text { storage) }\end{array}$ & $15 \%$ & $65 \%$ & $21 \%$ & $15 \%$ & $15 \%$ & $15 \%$ \\
\hline $\begin{array}{l}\text { Hydropower (run-of- } \\
\text { river) }\end{array}$ & $2 \%$ & $0 \%$ & $2 \%$ & $2 \%$ & $2 \%$ & $2 \%$ \\
\hline Geothermal & $0 \%$ & $0 \%$ & $0 \%$ & $0 \%$ & $4 \%$ & $8 \%$ \\
\hline Biomass & $0 \%$ & $1 \%$ & $2 \%$ & $2 \%$ & $2 \%$ & $2 \%$ \\
\hline Landfill gas & $1 \%$ & $1 \%$ & $1 \%$ & $1 \%$ & $1 \%$ & $1 \%$ \\
\hline Tidal & $0 \%$ & $0 \%$ & $0 \%$ & $0 \%$ & $3 \%$ & $5 \%$ \\
\hline Total renewable & $\mathbf{1 9 \%}$ & $\mathbf{8 0} \%$ & $\mathbf{8 0} \%$ & $\mathbf{8 0} \%$ & $\mathbf{8 0} \%$ & $\mathbf{8 0}$ \\
\hline
\end{tabular}

Assumptions for the modeling of these resources are summarized below, with additional details in Appendix C:

Wind: Profiles for hypothetical new wind plants were obtained from Alaska Renewables LLC, which assume 3.4-MW wind turbines with 100-meter hub heights. ${ }^{23}$ Fire Island Wind and Delta

\footnotetext{
${ }^{23}$ See appendix $\mathrm{C}$ for additional details
} 
Junction Wind were produced by NREL derived using NREL's renewable energy potential (reV) tool with NASA data for the year $2018 .{ }^{24}$

Solar: We used profiles generated by NREL for 4 locations in Alaska. Three locations use older resource data which are not time-synchronized with our meteorological year of 2018. The lack of time-synchronized data for PV is generally not desirable, as it can lead to over or underestimates of PV output during critical summer peak demand periods. However, the lack of strong summer peaks in Alaska mitigates this data limitation, and there was no alternative data available in the timeframe of the study.

Hydropower (conventional dam storage): Monthly water supply for existing hydropower generators was obtained from EIA-923. For future projects, we used estimated annual water availability from the Alaska Energy Authority, ${ }^{25}$ and this was divided into monthly averages using projects in the closest area.

Hydropower (run of river): We assumed $25 \mathrm{MW}$ of capacity deployable in the central region. A single representative hourly profile was applied to all projects. ${ }^{26}$

Tidal Energy ${ }^{27}$ We assumed up to 75 MW of tidal energy from Cook Inlet is deployable by 2040.

Geothermal: ${ }^{28}$ We assumed up to $50 \mathrm{MW}$ of geothermal energy from Mount Spurr is deployable by 2040 .

Biomass: We assumed adequate fuel (wood) for up to a $50 \mathrm{MW}$ plant with a 12,000 BTU/kWh heat rate. Assumed fuel costs were $\$ 9.375 / \mathrm{MMBTU}$.

Landfill gas: We did not consider landfill gas collection expansion and assumed only continued operation of existing facilities.

\subsection{Iterative Additions to Provide Resource Adequacy Under Normal and Outage Scenarios}

Because the power system envisioned in the $80 \%$ RPS scenarios rely heavily on the upgraded Alaska Intertie along with other transmission to access high-quality renewable resources, it is important to consider the possibility of extended transmission outages. Furthermore, it is important to consider outages of conventional generators for routine maintenance or unexpected

\footnotetext{
24 “reV: The Renewable Energy Potential Model,” NREL, https://www.nrel.gov/gis/renewable-energypotential.html.

${ }^{25}$ AEA memo of Sept 9, 2021, and additional correspondence.

${ }^{26}$ Assumption based on conversations with Joel Groves at Polarconsult Alaska. Profiles derived from "Response to Chugach RFP 21-23 Providing Conceptual Guidance on 'Category 2' Small Hydro Projects”

${ }^{27}$ This estimate was derived from conversations with ORPC. For more information, see this report: Kilcher, Levi, Michelle Fogarty, and Michael Lawson. 2021. Marine Energy in the United

States: An Overview of Opportunities. Golden, CO: National Renewable Energy

Laboratory. NREL/TP-5700-78773. https://www.nrel.gov/docs/fy21osti/78773.pdf.

${ }^{28}$ This estimate was derived from conversations with Cyrq Energy. For more information, see this report: WH Pacific. 2013. Renewable Energy in Alaska. Golden, CO: National Renewable Energy Laboratory. NREL/SR-7A4047176. https://www.nrel.gov/docs/fy13osti/47176.pdf.
} 
failures. Therefore, we tested each of the six scenarios (the no new renewable energy Base case and the five $80 \%$ renewable energy scenarios) under the following extended outage scenarios, where system components were unavailable for a several months during all periods of the year, including winter peak and the summer fire season. We established a criterion where each region was robust to the combination of three conditions, meaning all three things happen simultaneously:

- A region is isolated from the other zones for an extended period of time

- The extended loss of a region's single-largest generation facility (meaning the combined output of a plant that may have multiple generators)

- Shorter-term loss of additional generators based on an average forced outage rate of 7\%.

Specifically, these conditions correspond to the following cases:

- GVEA: Simultaneous loss of Alaska Intertie and the combined North Pole Plant, plus $7 \%$ random outage conditions on remaining generators

- Central: Simultaneous loss of both the Alaska Intertie and the Kenia Intertie, plus the entire Southcentral power project, plus 7\% random outage conditions on the remaining generators

- HEA: Simultaneous loss of the Kenai Intertie and Bradley Lake power plant plus 7\% random outage conditions on the remaining generators.

All scenarios, including the base case, assumed planned outages of all Railbelt power plants according to the 2022 maintenance schedules. ${ }^{29}$

We evaluated all scenarios to ensure load was met under these conditions. We did allow for reserve shortages, particularly as these conditions were already experiencing failures of the largest single system component, which sets the maximum reserve requirement.

In each case we iteratively added new fossil thermal capacity until all unserved load was eliminated in each region. We added new simple-cycle gas turbines with performance characteristics based on an LM6000 aeroderivative gas turbine operating on natural gas. ${ }^{30}$ In the base case we added $447 \mathrm{MW}$ of new capacity (largely in the Central and GVEA regions). In the RPS Scenarios we added between 223 MW (Scenario 2) and 367 MW (Scenario 1). The somewhat limited reduction in new fossil capacity in Scenario 1 was due to the assumption that the system must remain reliable even with the entire large hydropower plant in that scenario on outage for extended periods of time. The more dispersed and smaller resources in Scenario 2 reduced the amount of fossil capacity needed for resource adequacy under extended outage conditions. The reduction of new fossil capacity needed in the $80 \%$ RPS scenarios compared to the Base Case (between 80 and $224 \mathrm{MW}$ ) was achieved because much of the capacity added, particularly hydropower, geothermal, tidal energy, and biomass, provided resource adequacy as discussed in Section 5.

After the iterative additions and simulations, we arrived at the six portfolios that provide an $80 \%$ RPS. It is important to note that the $80 \%$ RPS is achieved under "normal" operating conditions

\footnotetext{
${ }^{29}$ Maintenance schedules provided by AEA, 2022.

${ }^{30}$ Because of the increased operation of these units in the base case, we also considered a case with more efficient combined-cycle units in our fuel savings estimates in Section 5.
} 
with annual average outage conditions. The extended outage cases establish reliable operation, but we do not attempt to achieve an $80 \%$ renewable energy under extended or extreme outage conditions (see Section 4). Table 4 provides the final portfolio for the six modeled scenarios.

Table 4. Final Portfolio: Capacity (MW)

\begin{tabular}{|c|c|c|c|c|c|c|}
\hline $\begin{array}{l}\text { Technology (Existing } \\
\text { and New) }\end{array}$ & $\begin{array}{l}\text { Base } \\
\text { Case }\end{array}$ & Scenario 1 & Scenario 2 & Scenario 3 & Scenario 4 & Scenario 5 \\
\hline Wind & 45 & 202 & 826 & 847 & 847 & 777 \\
\hline Solar & 1 & 30 & 258 & 456 & 150 & 132 \\
\hline Hydropower (storage) & 186 & 866 & 324 & 248 & 248 & 186 \\
\hline $\begin{array}{l}\text { Hydropower (run-of- } \\
\text { river) }\end{array}$ & 25 & 0 & 25 & 25 & 25 & 25 \\
\hline Geothermal & 0.4 & 0.4 & 0.4 & 0.4 & 25.4 & 50.4 \\
\hline Biomass & 0 & 50 & 50 & 50 & 50 & 50 \\
\hline Landfill gas & 7 & 7 & 7 & 7 & 7 & 7 \\
\hline Tidal & 0 & 0 & 0 & 0 & 50 & 75 \\
\hline Battery Storage & 163 & 163 & 163 & 163 & 163 & 163 \\
\hline Fossil thermal & 2,048 & 1,968 & 1,824 & 1,911 & 1,897 & 1,890 \\
\hline Total & 2,474 & 3,286 & 3,477 & 3,707 & 3,462 & 3,355 \\
\hline
\end{tabular}




\section{Findings}

In this section, we discuss our two overall findings, including three important subfindings to our first overall finding.

Overall Finding 1: Multiple pathways exist for achieving an 80\% RPS, and reliability can be maintained with appropriate system engineering.

The overarching conclusion of this analysis is there are likely multiple pathways to achieving an $80 \%$ RPS while maintaining reliable service. All modeled scenarios can achieve $80 \%$ renewable energy while maintaining balance of supply and demand with no unserved energy or reserve shortages during normal operations. The system can also serve load under severe outage conditions in all cases, although the 80\% RPS may not be achieved if very long outages were to occur on some parts of the grid. This finding depends on the continued use of best practices and the engineering approaches historically deployed by Alaska's Railbelt utilities, particularly with regard to the use of state-of-the-art (but proven) technologies.

Within this overall finding, we identify three key subfindings that are common to all scenarios in achieving an $80 \%$ while maintaining reliable operation.

\section{Key Subfinding 1: A variety of resources, including fossil-fueled generators, are used to provide reliable operation.}

Load balancing in $80 \%$ renewable scenarios is achieved during all hours of the year via a combination of renewable resources, including variable renewables, storage, and remaining fossil resources. Figure 6 illustrates the generation resources used to meet demand in four separate one-hour periods, showing the range of contributions from various generation technologies. Figure 6(a) shows generation resources utilized during the hour of peak demand for the six scenarios during normal operation. Peak demand days are typically the most challenging for utilities; however on this day, there was significant wind output assuming 2018 meteorology. During other periods of significant demand, however, variable resources including wind and solar may not be as available. Figure 6(b) shows an hour of similarly high demand, but with much lower output of wind and solar. These conditions increase the contribution of fossil thermal units. Figure 6(c) shows an hour of very high wind and solar output, where renewable resources provide nearly all of the system's electricity. 

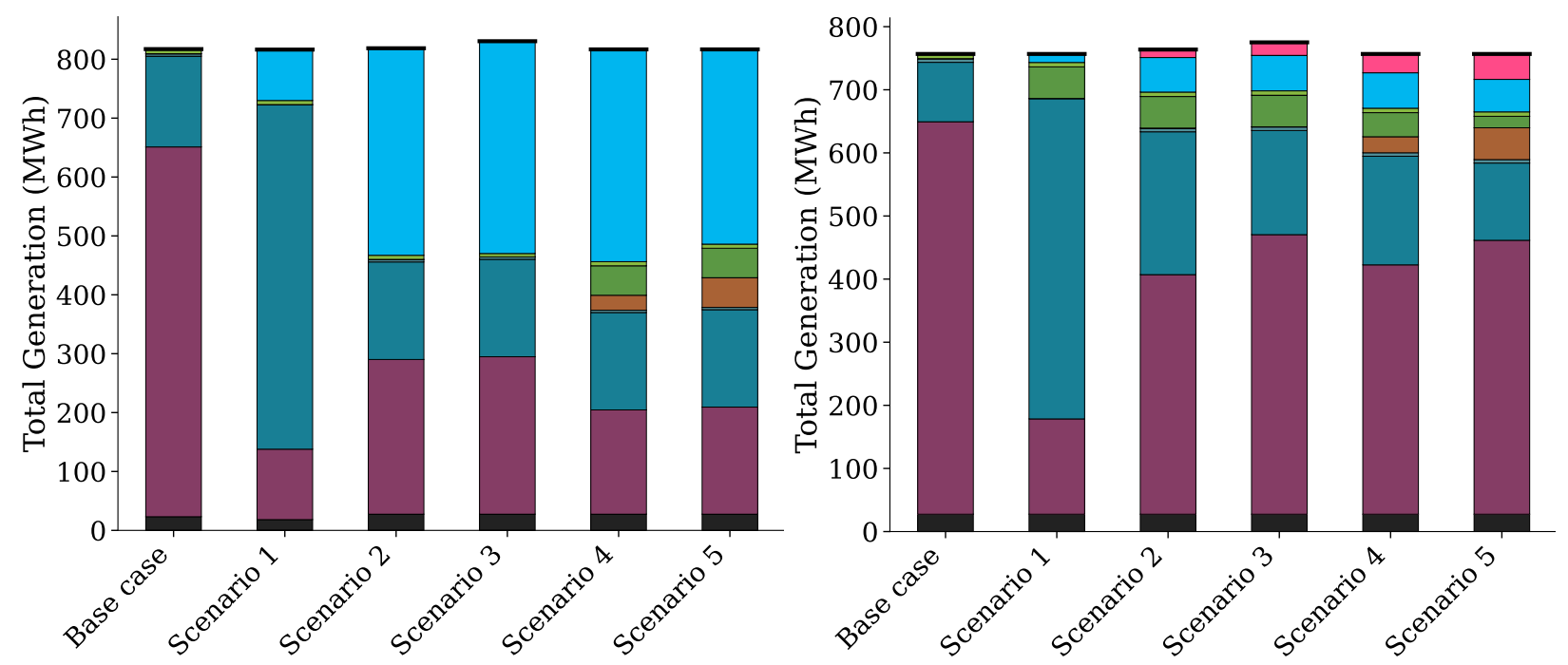

(a) Peak Demand Hour

(b) A High Demand Hour with Low Wind and Solar Output

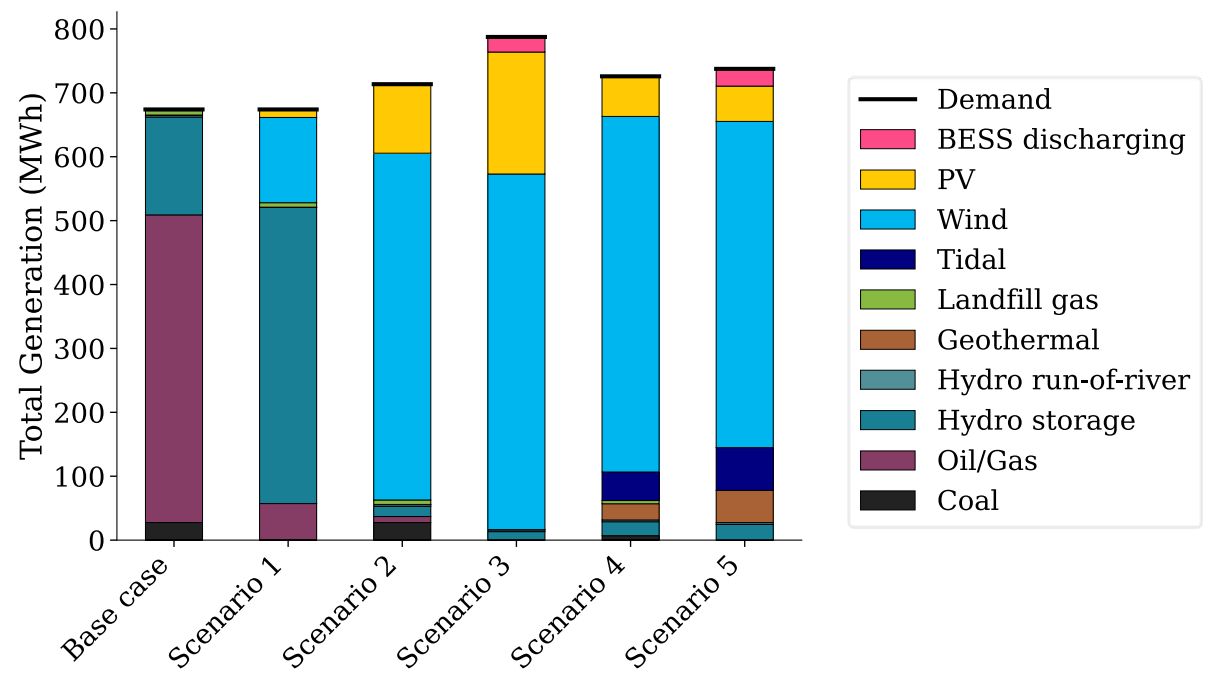

(c) An Hour with High Wind and Solar Output

Figure 6. Stacked bar charts of sources of generation during three hours for the six scenarios

While over the entire year renewables provide (on average) $80 \%$ of the total supply, the contribution in any given hour ranges considerably - from as little as $11 \%$ to $100 \%$, and this contribution also varies by region. ${ }^{31}$ Along with storage (see Key Subfinding 2), fossil and hydropower plants vary output on a daily and a seasonal basis to meet demand, similar to operation in the current grid but with increased variations in the cases with greater use of wind and solar.

Figure 7 illustrates the operation of the system for the day with peak demand periods in the "bookend" cases (Scenarios 1 and 3) with the least and most contributions from wind and solar. These curves are referred to as dispatch "stacks" because they add up the contribution of

\footnotetext{
${ }^{31}$ Minimum renewable contribution typically occurs during the periods of lowest hydropower contribution in the winter, while maximum occurs during the spring runoff.
} 
different resources in each interval, and show how the contribution will change over time, including how some units are turned on and off as needed. The top curve shows Scenario 1, where hydropower provides the majority of the electricity. The bottom curve (Scenario 3 ) shows greater use of fossil resources to meet peak demand.

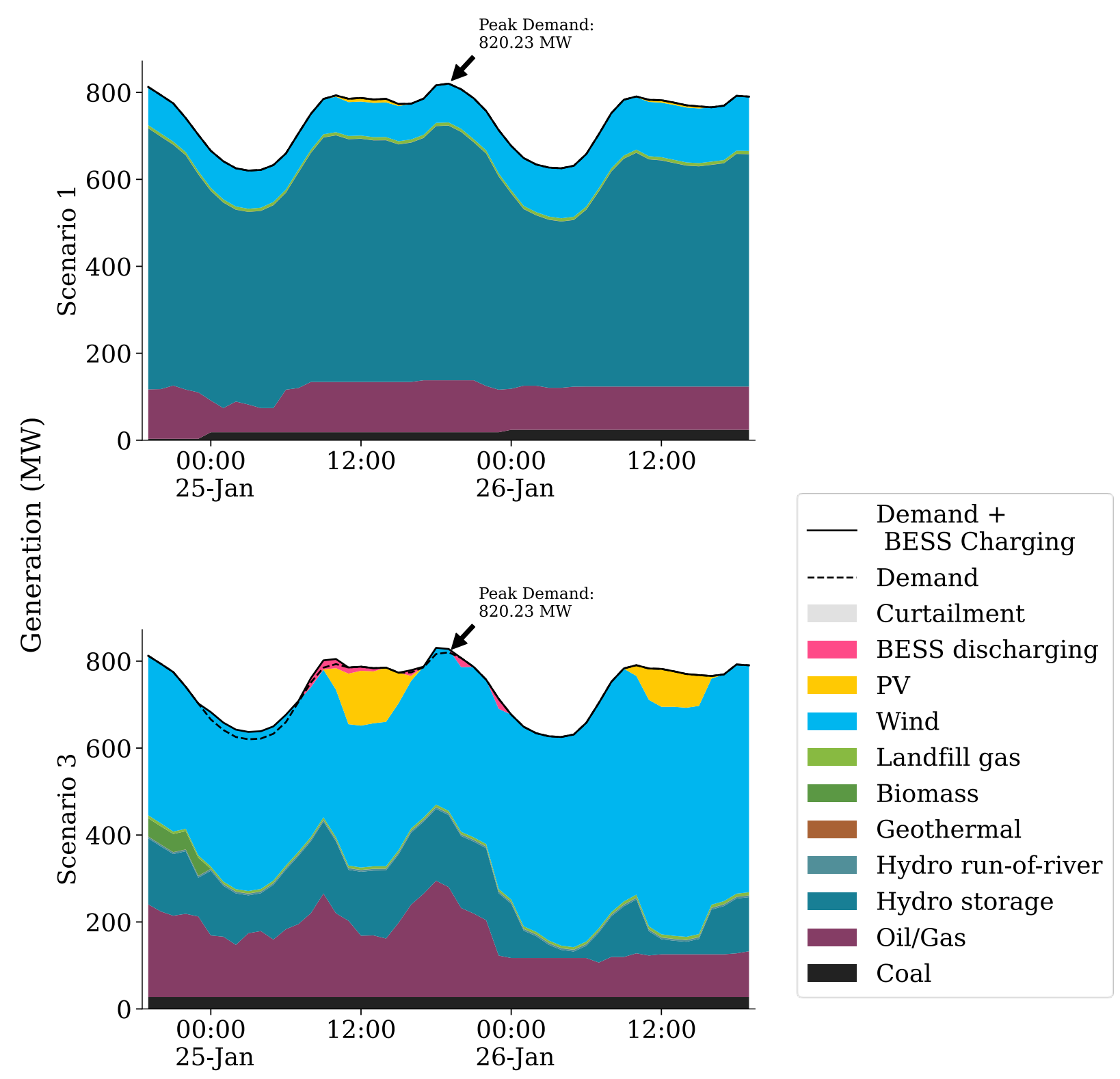

Figure 7. System dispatch on the peak demand day in Scenarios 1 (top) and 3 (bottom)

Key Subfinding 2: Flexible Hydropower and Storage are important elements of balancing supply and demand and providing fast response to system outages.

In the cases with more wind and solar, there is greater variability of the resource mix over various time scales. The impact of this variability is often expressed in terms of net load, or the normal load minus the contribution of variable generation resources such as wind and solar and represents the load that must be met with the remaining resources. Figure 8(a) shows the normal 
load (orange), total wind and solar (gray) and the resulting net load (yellow) in Scenario 1 (with the highest hydropower contribution) during a four-day period of high electricity demand. The relatively modest contribution of wind and solar has minimal impact on the net load shape. Figure 8(b) shows the same time period for Scenario 3 (largest variable generation contribution), where the greater levels of wind and solar produce a dramatic reduction and increased volatility in net load.

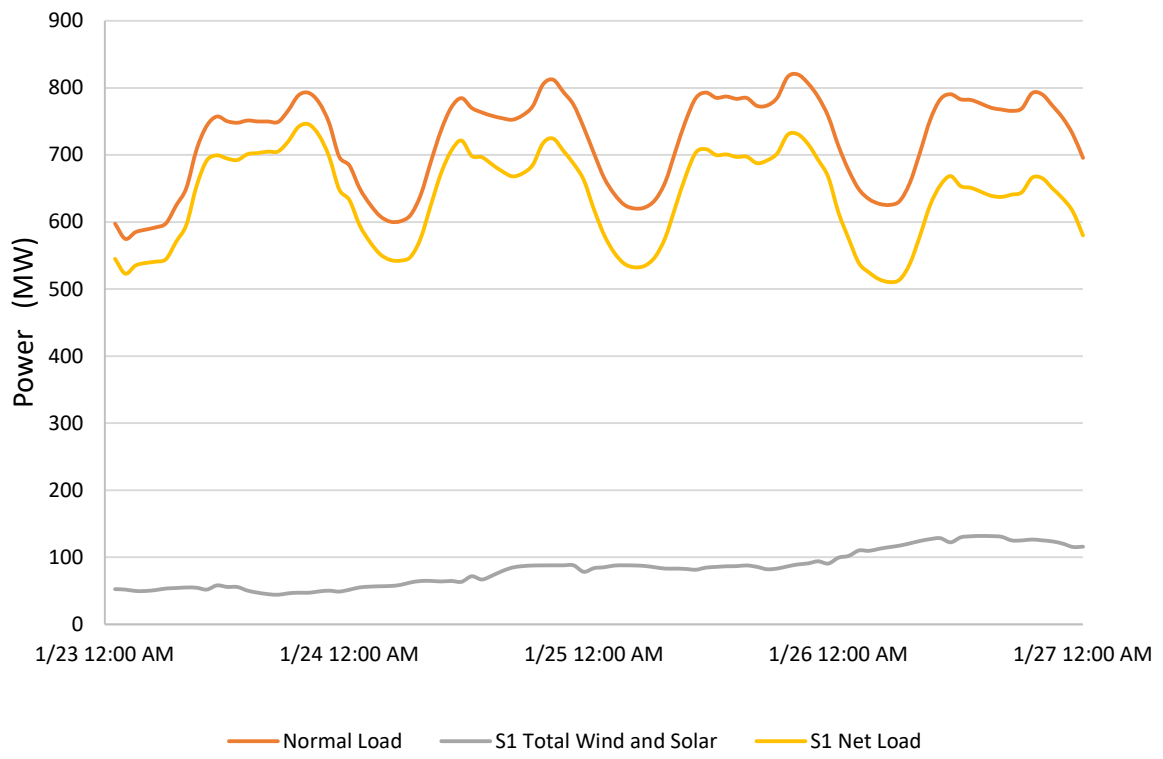

a) Scenario 1 (largest hydro and lowest wind and solar)

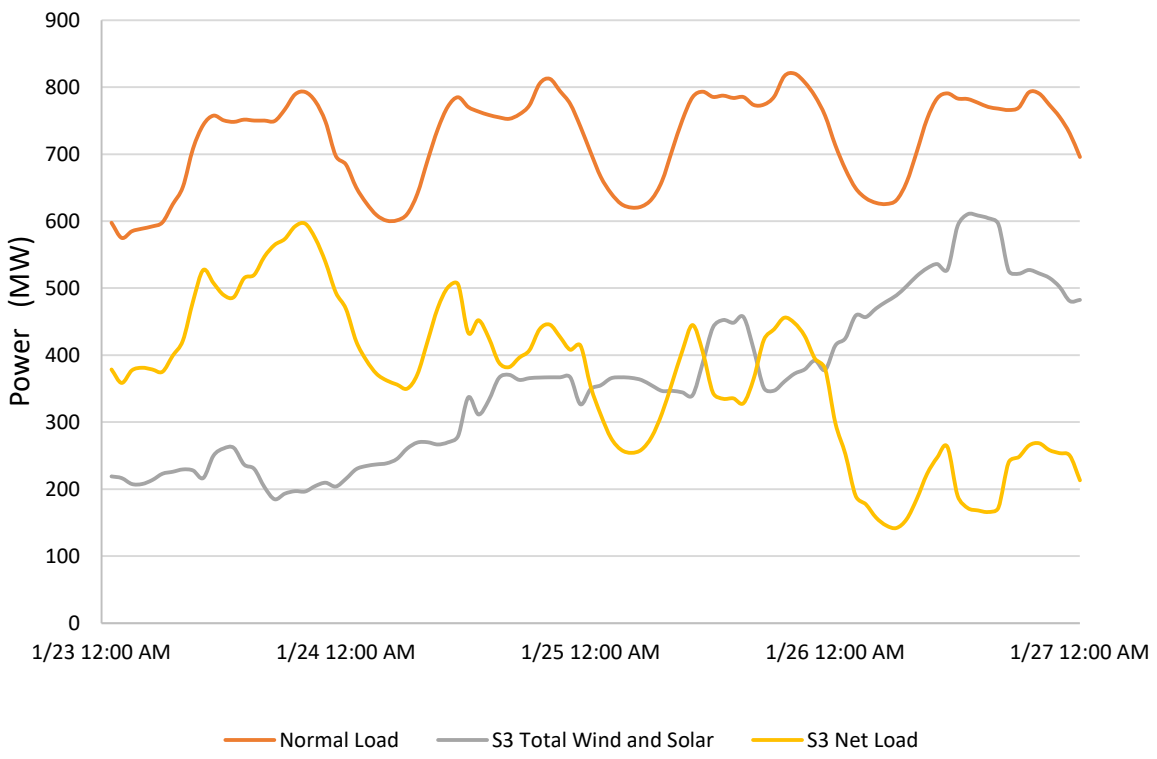

b) Scenario 3 (largest amount of wind and solar)

Figure 8. The impact of wind and solar on net load during a four-day period in January

Flexible renewable resources such as hydropower, along with energy storage, help address this variability in net load. Figure 9a shows the operation of the Bradley Lake hydropower plant in Scenario 3. The left figure plots the same four-day period as in Figure 8. The plant varies output 
(green) to follow the net load, occasionally reducing output to accommodate the periods with large supply of wind and solar. While it is often increasing or decreasing output, the rate of increase is no more than half of the plants rated capacity in any hour in this period. The ability of the plant to operate over a large output range is an important component of scenarios with large amounts of wind and solar. The right curve shows another period where the plant operates at its minimum output level for several hours at a time during extended periods of very low net load. There are also periods during the spring runoff when the plant operated at very low levels for days at a time. The difference in operation that results from large deployments of wind and solar is illustrated in Figure 9(b). This duration curve represents the output of the plant sorted by value over an entire year, and it indicates how often the plant was operating at a certain output level. The figure shows both Scenario 1, and Scenario 3, where the plant spends a considerable amount of time operating at low levels when large amounts of wind and solar are available to serve load. In general, the Bradley Lake hydroelectric plant spends more time operating at extreme high and low levels of output in the scenarios with more contribution from wind and solar.
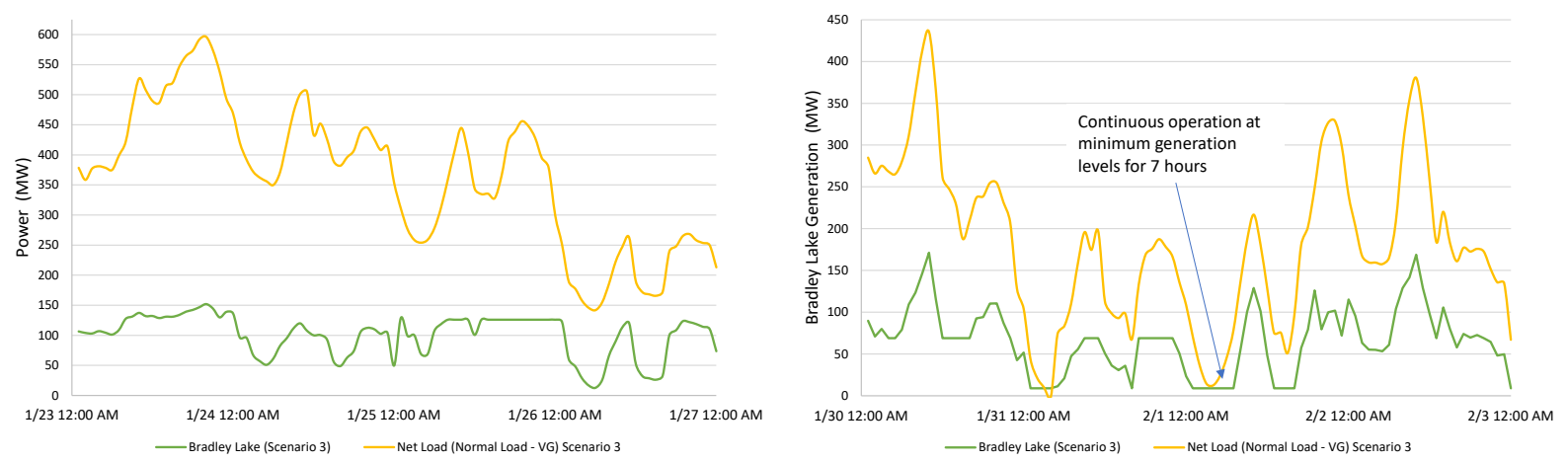

(a) Hourly Operation during a four-day period in Scenario 3

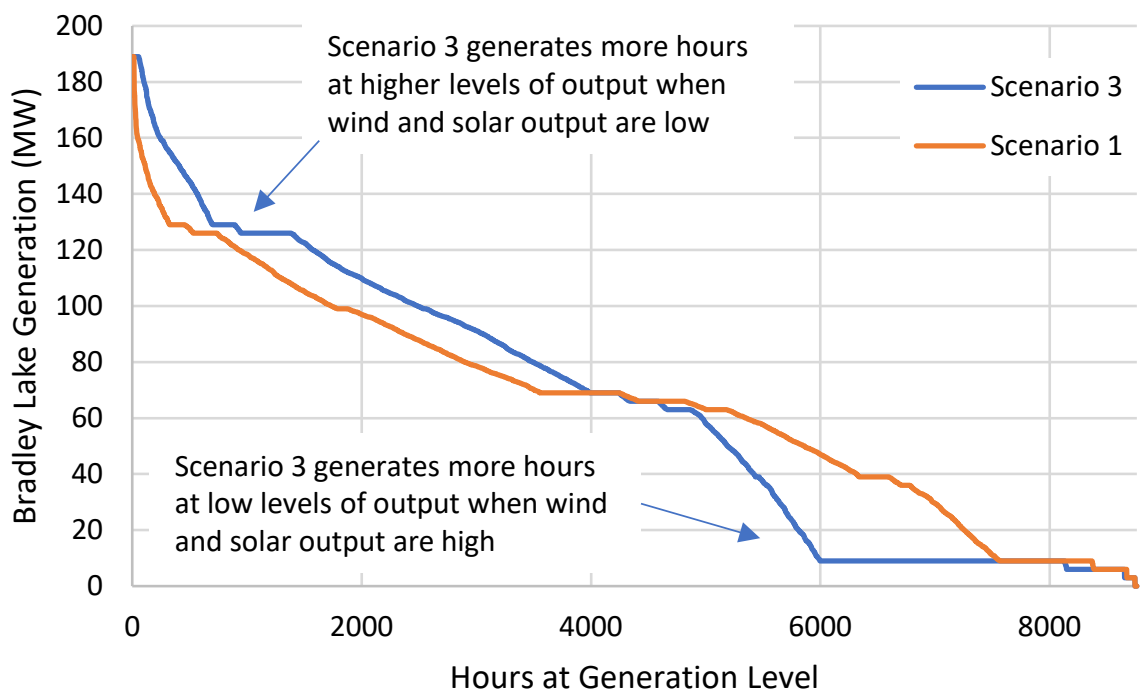

(b) Generation Duration Curve

Figure 9. Operation of the Bradley Lake hydroelectric plant

Overall, this operation shows how the existing and potential new flexible hydropower can help further deployment of wind and solar. Other generation technologies, such as new flexible 
geothermal could also play a role in balancing variability. The inherent storage in these plants helps balance the system load and reduces the amount of dedicated storage needed for this purpose. The amount of wind and solar in several scenarios can potentially lead to curtailment, or overgeneration, when the supply of renewable resources, combined with flexibility limits of thermal power stations, results in more electricity than can be used. This often occurs during periods of low demand. Curtailment of wind and solar is not technically difficult to manage by reducing the output of these resources in a manner similar to that of other generation resources, but it results in unusable energy and decreases the economic value of these resources. However, the Railbelt power system, which features flexible hydropower, flexible thermal plants, and existing or planned levels of energy storage, can accommodate deployments of wind and solar that provide about $60 \%$ of annual demand with limited curtailment. In the $80 \%$ renewable scenarios, we include three battery storage systems (one in each zone), all of which are currently under consideration.

Figure 10 illustrates how the levels of storage already under consideration can help mitigate potential curtailed energy and balance renewable energy supply. Figure 10(a) shows the total supply of wind and solar (orange) in Scenario 3, along with the normal demand for electricity (black). During several hours on two days, the supply of wind and solar exceeds the electricity demand, resulting in curtailed energy (yellow). However, the addition of storage significantly reduces the amount of curtailed energy. Figure 10(b) shows the operation of storage units (blue line) in the same scenario, showing how these units charge during periods of lowest net load, substantially decreasing curtailment during these hours, and discharging during periods of highest net demand.

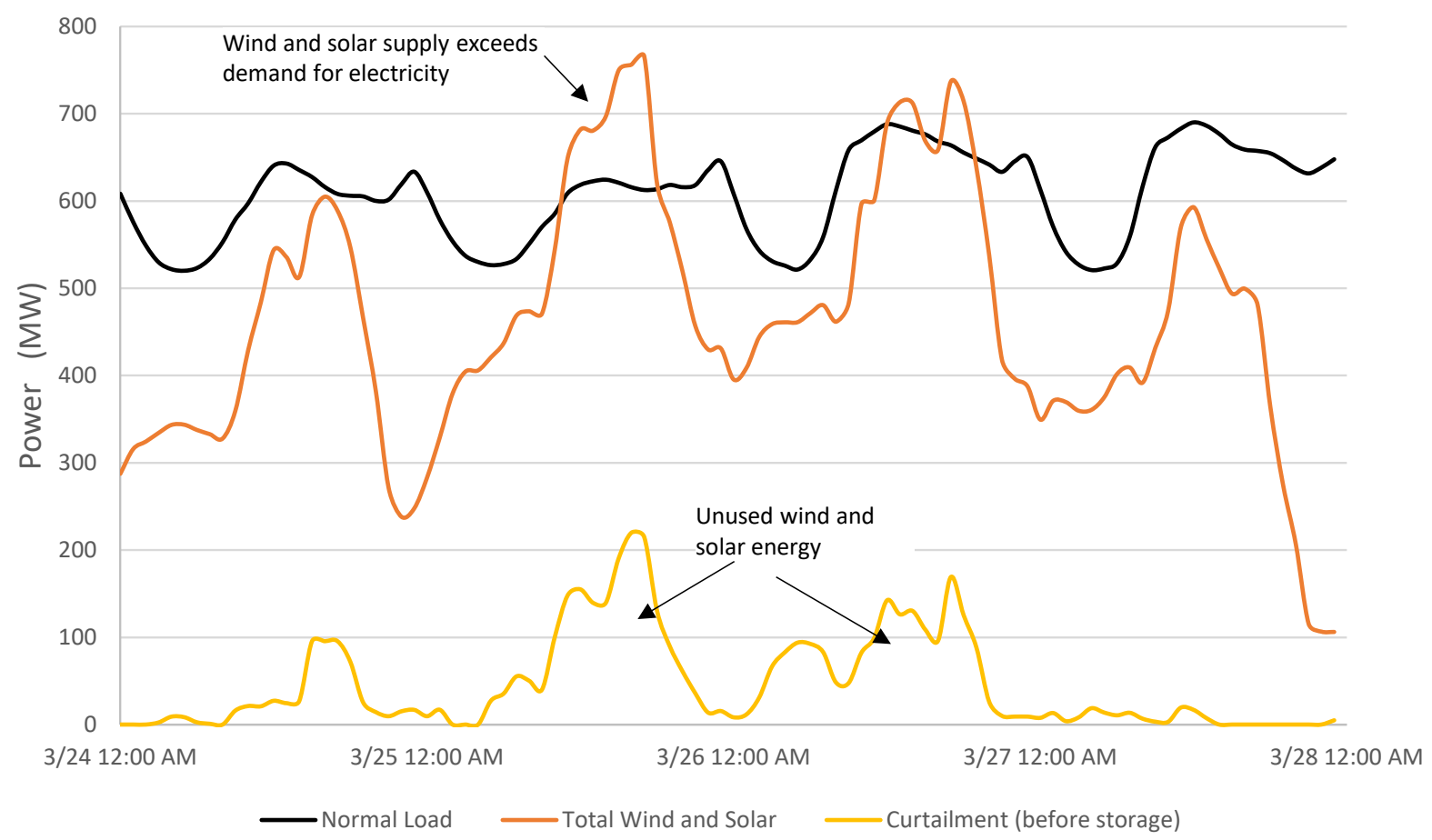

(a) Net load in Scenario 3 resulting in periods of curtailed energy 


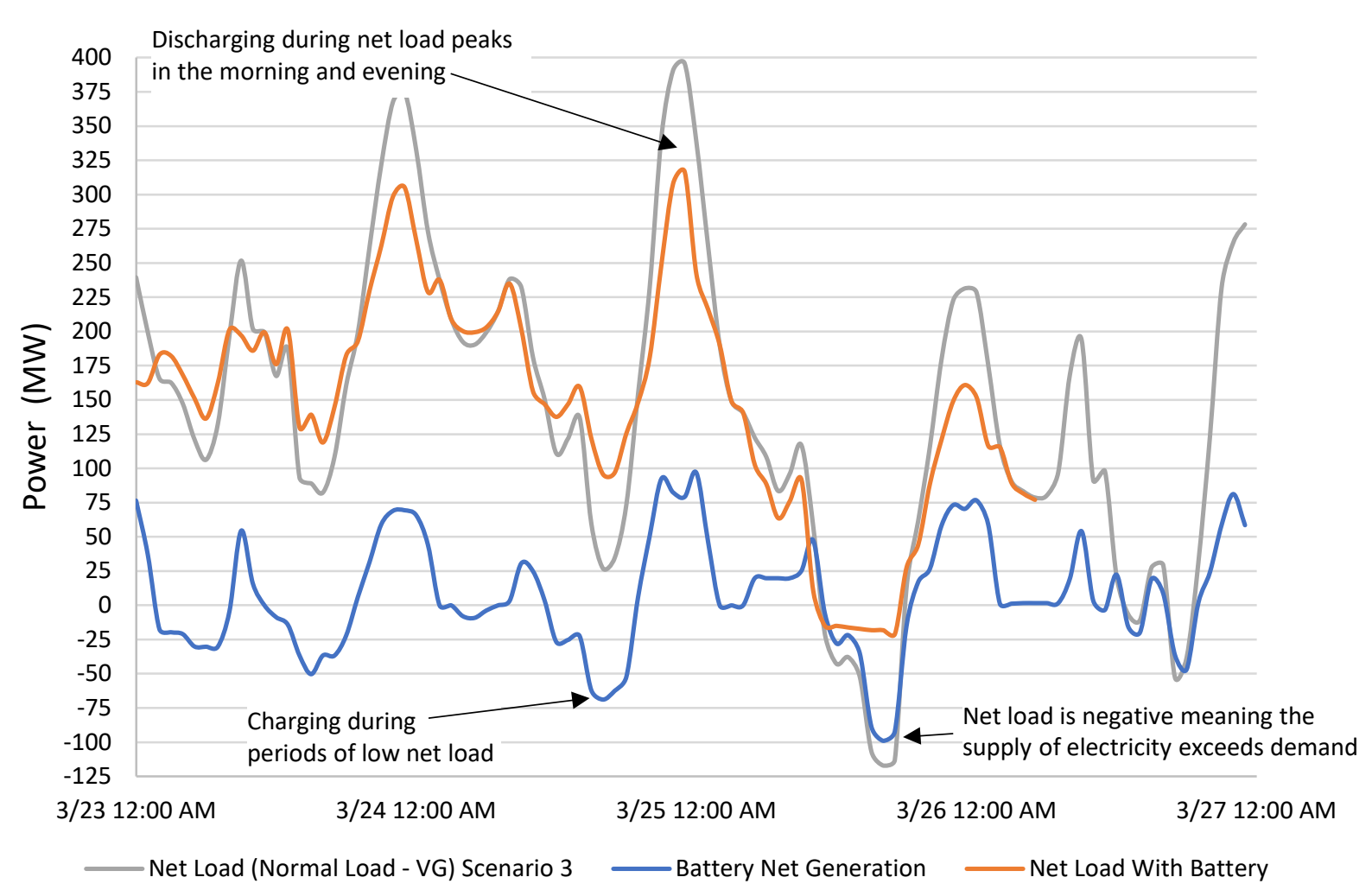

(b) Storage Operation

Figure 10. Curtailment and storage use patterns

In addition to shifting supply of renewable resources and avoiding unusable generation, storage also provides fast responding operating reserve. An important component of maintaining system frequency stability is ensuring the system can respond to a loss of a generation resource, such as a transmission outage. The Railbelt system relies on three elements to maintain a stable frequency in the moments following an outage: the inertia in rotating generators in fossil and hydropower generators, the ability of these generators to respond to changes in frequency via primary frequency response, and fast response from batteries. Alaska was one of the pioneers in the use of batteries in this application, and this role will likely increase in scenarios which include more wind and solar deployment. Figure 11 shows the fraction of demand met by wind and solar during January and February of the year in Scenario 3. This shows the significant variability of the supply, as well as periods where they provide much of the generation. During periods of high wind and solar output, thermal generators will often be turned off, reducing the amount of inertia in the system. This increases the need for very fast responding resources such as batteries. Furthermore, as shown by other U.S. power systems with large wind and solar deployments, wind and solar themselves can also supply frequency responsive services. 


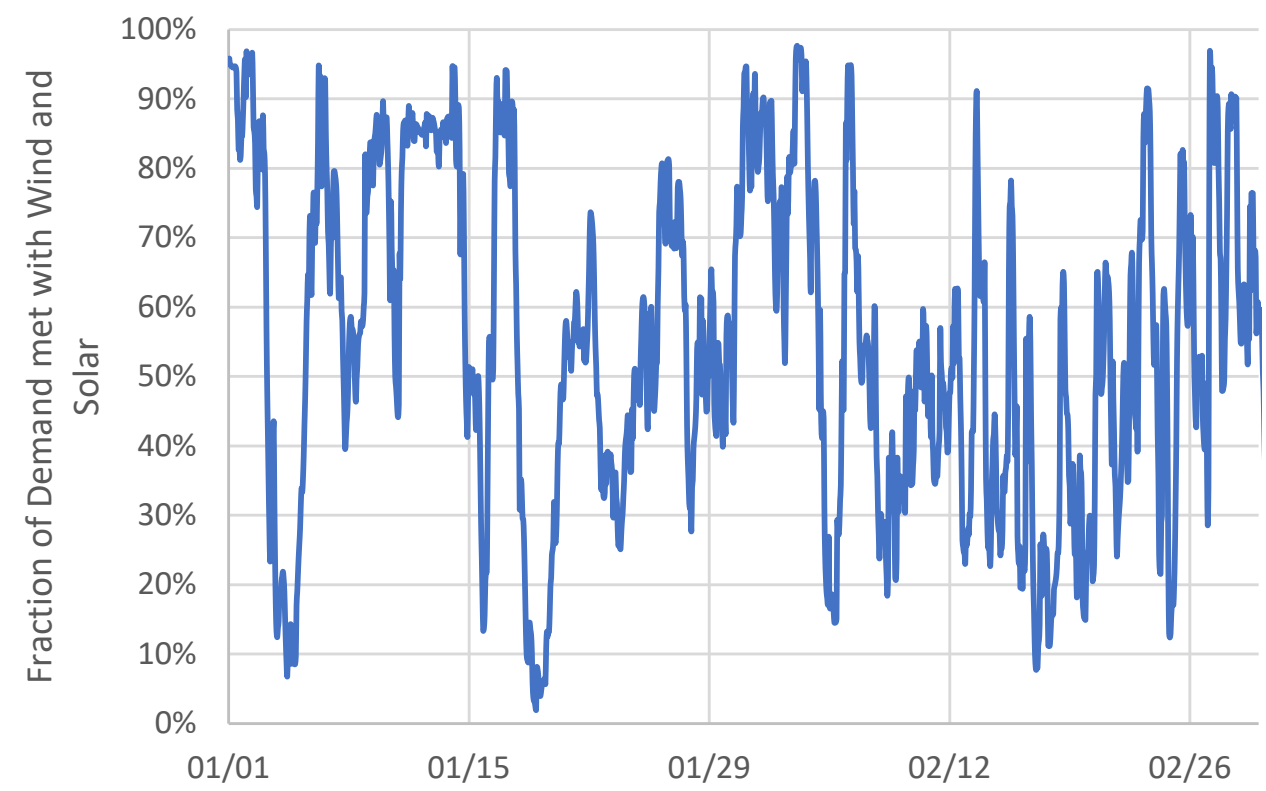

Figure 11. Fraction of demand met by wind and solar in the first two months of the year in Scenario 3

Key Subfinding 3: Transmission is an important contributor to achieving the $80 \%$ RPS.

Transmission is another important contributor to achieving the $80 \%$ RPS. Additional transmission will likely be needed to connect new renewable resources to existing transmission and load centers, and all scenarios rely significantly on an upgrade to the Alaska Intertie. We did not evaluate the specific engineering requirements, costs, or timing of an such an upgrade, and there may be alternative transmission approaches to deliver energy from resource regions in the north to load centers in the south.

Figure 12(a) illustrates the operation of the Alaska Intertie. Figure 12(a) shows a flow duration curve, or the numbers of hour per year power flows on each intertie at a certain rate. A positive value on the Alaska Intertie corresponds to a north to south flow. In Scenario 1, the line flows at its maximum rating nearly the entire year, due to the presence of the large hydro project on the north side of the line. In all the other cases, there is flow in both directions, depending on the supply of resources in the various regions. Figure 12(b) plots a duration curve of the Kenai Tie, where positive values indicate west to east flow off the peninsula.

Figure 12(c) illustrates why the flows on the Alaska Intertie vary in direction, and the potential value of increased transmission capacity. It shows the hourly flows in Scenario 3 for a 4-day period. During the first two days, below average wind conditions in GVEA (orange line) result in a deficit of supply (a high net load in gray). As a result, GVEA imports electricity from hydropower and other resources, represented by a negative value on the black line. However, starting on January $26^{\text {th }}$, it becomes much windier in GVEA, resulting in a surplus of wind generation. This excess supply can be sent to the south (positive flows), where hydropower plants can reduce output, and save the water for another period where wind conditions are lower. 


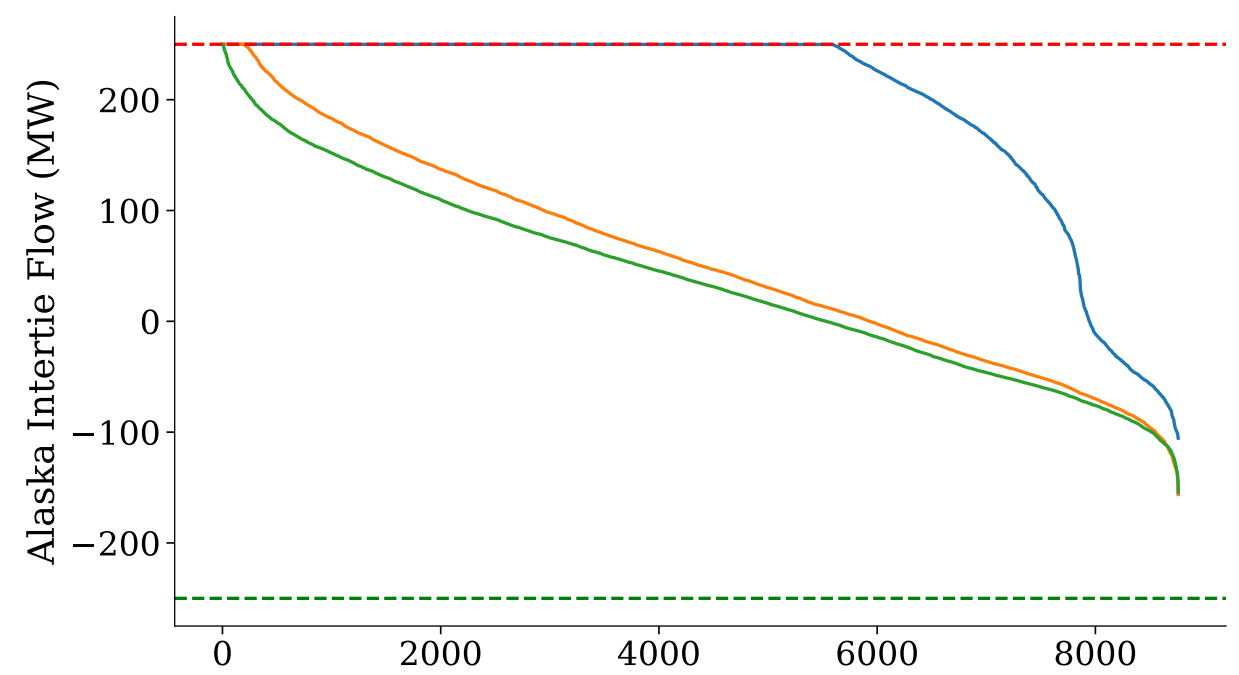

Hour of the year

(a) Annual flows (duration curve) on the Alaska Intertie

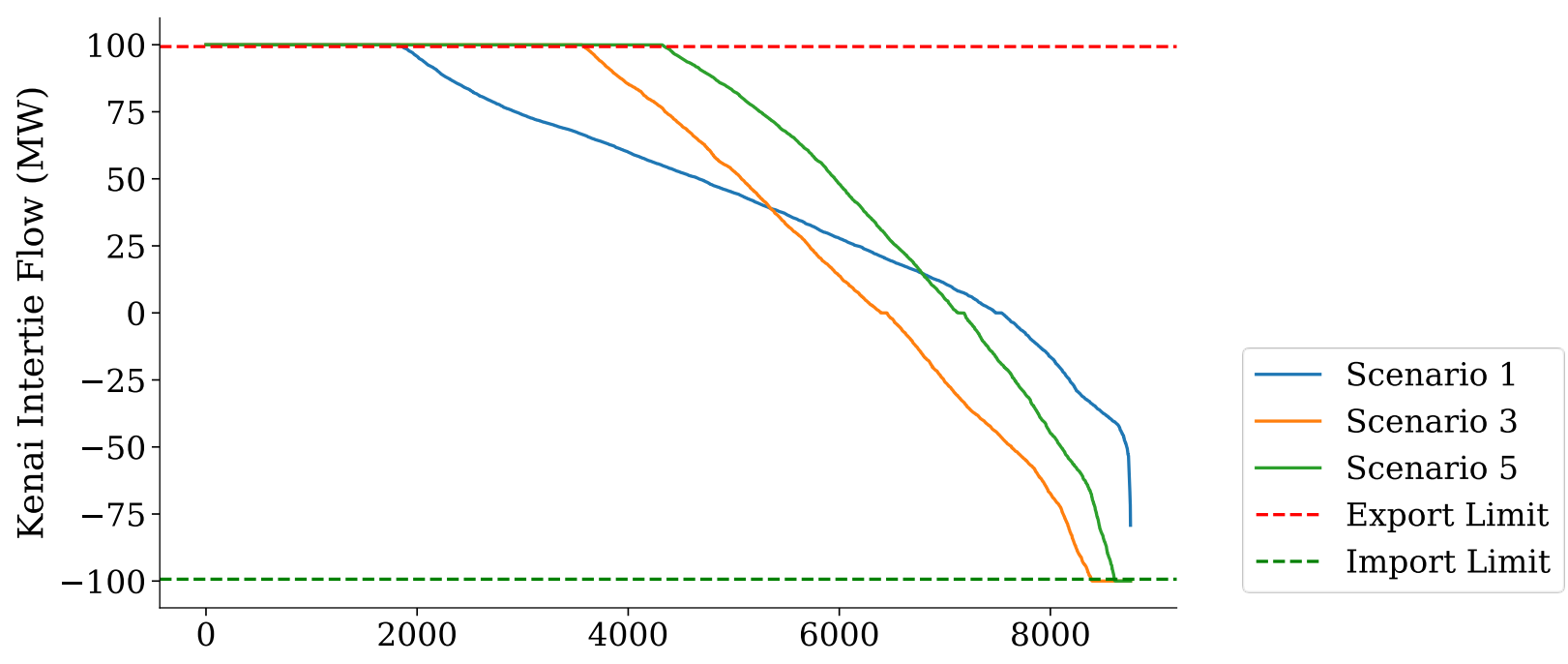

Hour of the year

(b) Annual flows (duration curve) on the Kenai Intertie 


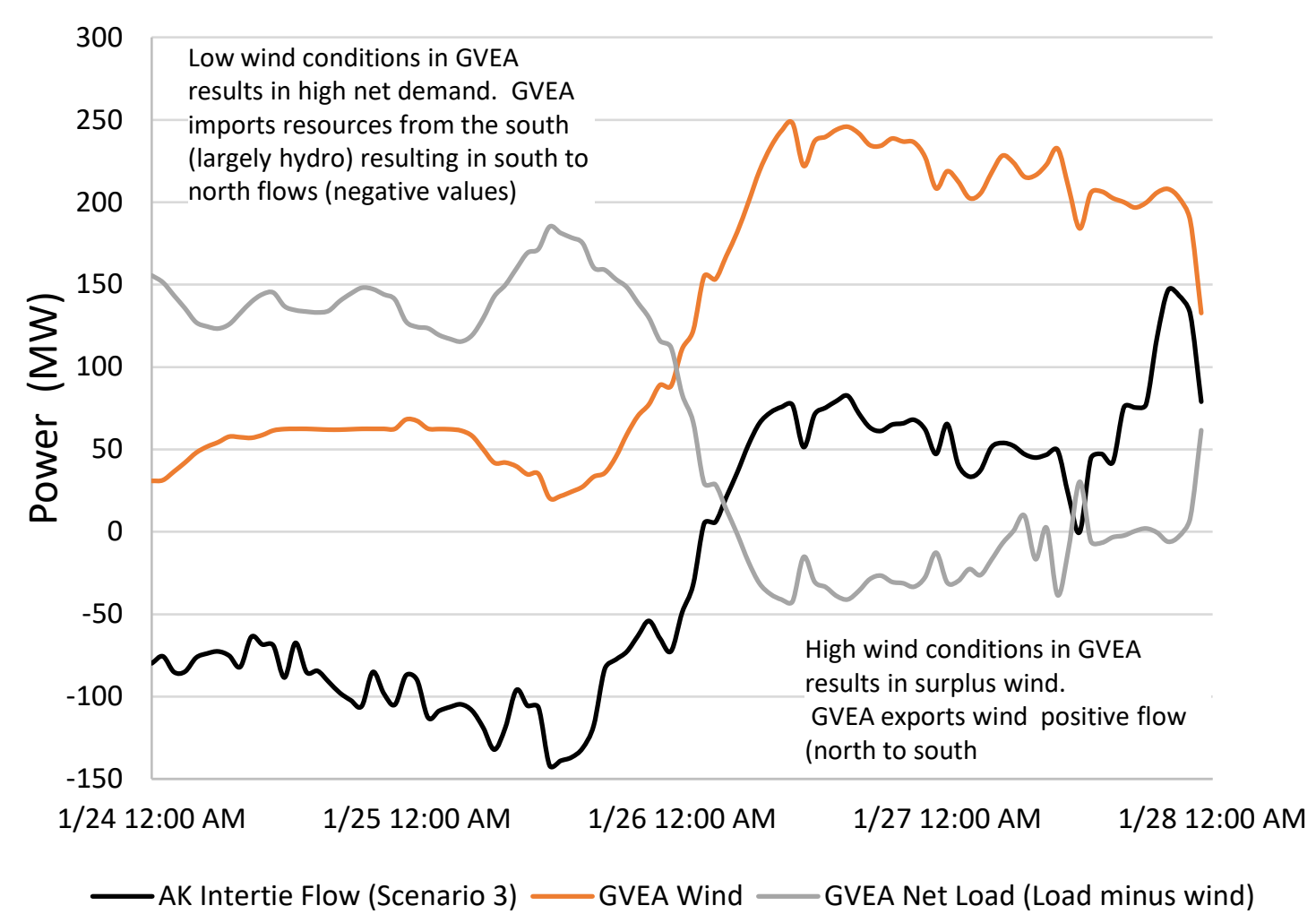

(c) Hourly flows

Figure 12. Flows on the Alaska Intertie

We performed an additional test, upgrading the Alaskan Intertie to an estimated upper range of its thermal limit. ${ }^{32}$ Applied to Scenario 1, this allowed an additional $134 \mathrm{GWh}$ to flow south from the large hydro project to the Central region. This would theoretically allow the system to reach the $80 \%$ RPS goal in that scenario with roughly 30-40 MW less wind capacity.

\section{Overall Finding 2: An $80 \%$ RPS achieves a substantial reduction in fuel costs, which could be compared to capital cost expenditures for a comprehensive impact assessment.}

The Base Case system assumptions in 2040 results in about 4,200 GWh of fossil-generated electricity, corresponding to roughly 30-40 trillion BTUs of fuel, including natural gas, fuel oil, and coal. ${ }^{33}$ The $80 \%$ RPS scenarios reduce fossil generation by about $75 \%$. Figure 13 illustrates the fossil generation in 2040 by region across the various scenarios. The total fossil generation across the five $80 \%$ RPS scenarios is almost identical, but there are some regional differences, driven largely by the location of the new renewable generators. Scenario 1 largely eliminates fossil generation in GVEA, due to the large hydropower project, while the tidal generation facility in Scenario 5 largely replaces fossil generation in HEA.

\footnotetext{
${ }^{32}$ Upper thermal limit provided by GVEA, 2022.

33 The range represents uncertainty in the likely mix of generator types used in the Base Case scenario. It represents a fleet-wide average fuel consumption (heat) rate of between 8,000 and 9,500 BTU/kWh, which considers a mix of efficient combined-cycle generators, and less efficient simple cycle or reciprocating engine generators.
} 


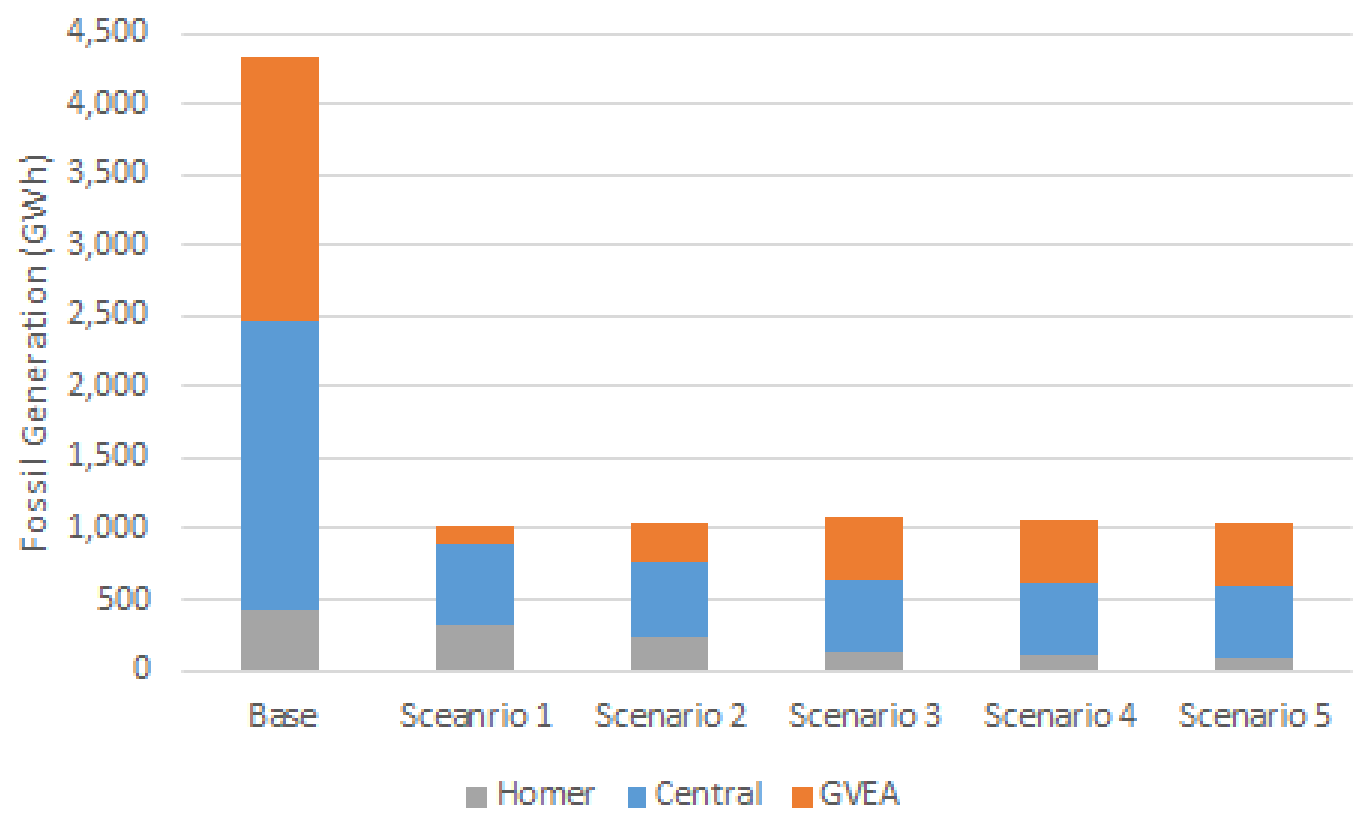

Figure 13. Annual fossil generation in 2040 by region

This reduction in fuel use represents an annual savings of about 25-31 trillion BTUs in 2040, which can be translated into an annual cost savings. The actual cost savings will depend highly on assumed fuel costs, fuel mix, and generator properties. Figure 14 illustrates the annual fuel saving in 2040 under various fuel price trajectories.

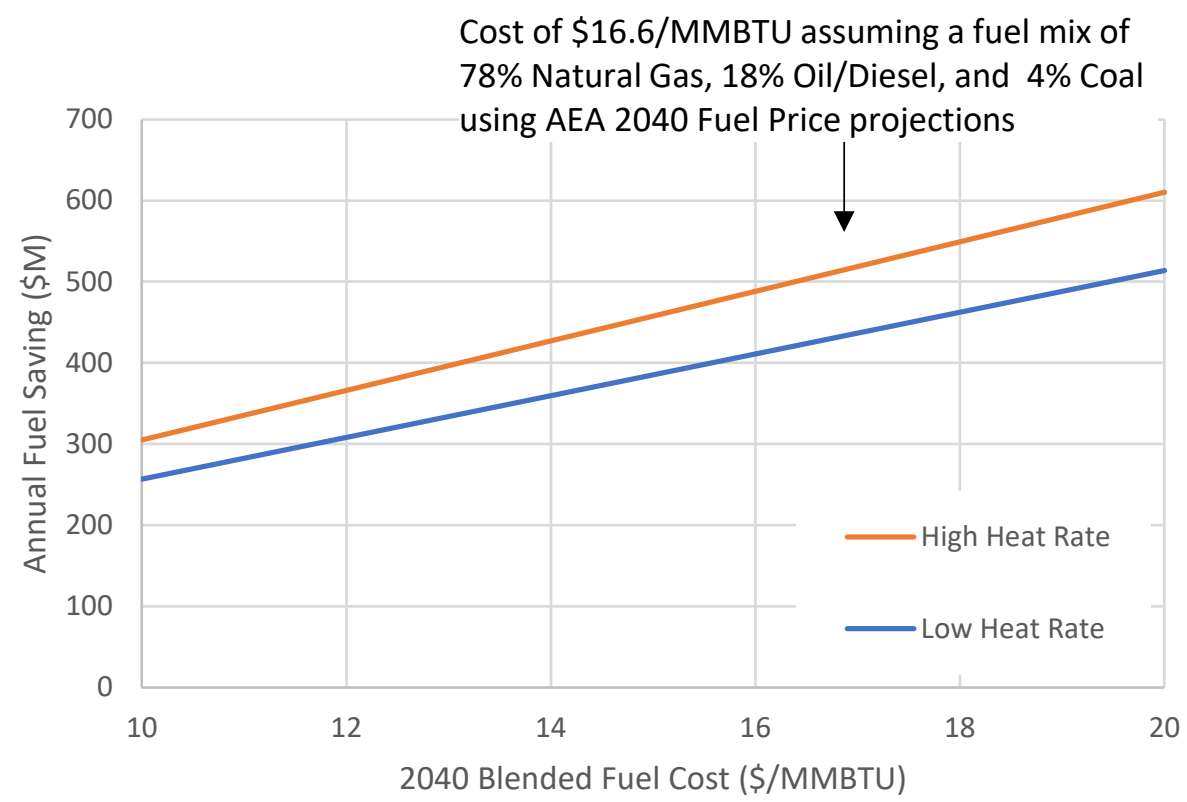

Figure 14. Annual fuel savings 
For reference, using the estimated fuel mix for the remaining generators in 2040 produces a blended cost of about $\$ 16.60 /$ MMBTU. ${ }^{34}$ Using this value results in an annual savings of $\$ 426$ to $\$ 506$ million.

A total comparison of costs between the base case and 80\% RPS case requires analysis of differences in capital cost expenditures. Figure 15 illustrates this conceptually. All scenarios require continued investment in the existing distribution network, and common investments across the scenarios, such as our assumption of the Bradley Lake expansion and Alaska Intertie upgrades. These are shown as the identical height bars in Figure 15. In addition to this, we have the costs associated with the fixed (capital) and variable (largely fuel) components of future additions. The annualized costs of fuel (plus the additional capacity cost of fossil capacity needed for reliability) are dramatically lower in the $80 \%$ RPS cases. The primary uncertainty is the additional capital costs associated with the renewable resources. This is represented by the blue bar, which could result in lower or higher total costs. Detailed analysis is needed for this component, including the differences between various $80 \%$ RPS scenarios.

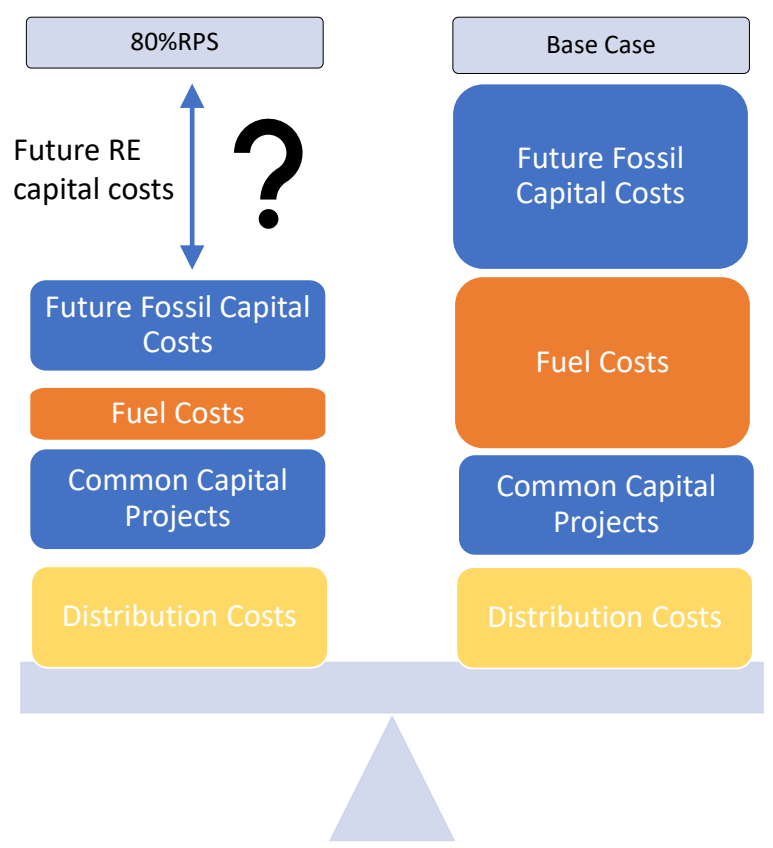

Figure 15. Conceptual illustration of analysis needed to identify impact on total system costs

\footnotetext{
${ }^{34}$ This is based on deriving about $78 \%$ of fossil generation from natural gas, $18 \%$ from liquid fuels and $4 \%$ from coal. The coal value is based on the simulations performed in this work, which are purchases of generation from combined heat and power plants at the University of Alaska-Fairbanks and a few other locations. The remaining split is determined by the relative contribution of those resources in 2020 using EIA-923 data.
} 


\section{Next Steps}

In summary, this analysis includes production cost modeling across Alaska's Railbelt to estimate the ability of the system to balance supply and demand over a single year using a single year of simulated weather.

Further work needed for a full integrated resource study includes the following:

- Deriving a least-cost optimal mix of resources by applying capacity expansion modeling and evaluating and life-cycle costs across various scenarios

- Modeling transmission options for the Alaska intertie upgrades and assessing transmission alternatives

- Obtaining load projections and time-synchronized solar data

- Modeling hydropower water budgets and the variable efficiency of partial load operation of turbines under scenarios with increased variability

- Modeling natural gas and other fuels, particularly in GVEA

- Completing detailed outage scheduling and simulations to determine impact of forced and planned outages on achieving $80 \%$ renewable energy

- Completing all aspects of power flow modeling, including steady state and dynamics, stability analysis, contingency event analysis, etc.

The preliminary analysis represented in this draft report and the additional analysis components will allow for completion of a detailed renewable energy road map for Alaska's Railbelt. 


\section{Appendix A. Resource Maps for Alaska's Railbelt}

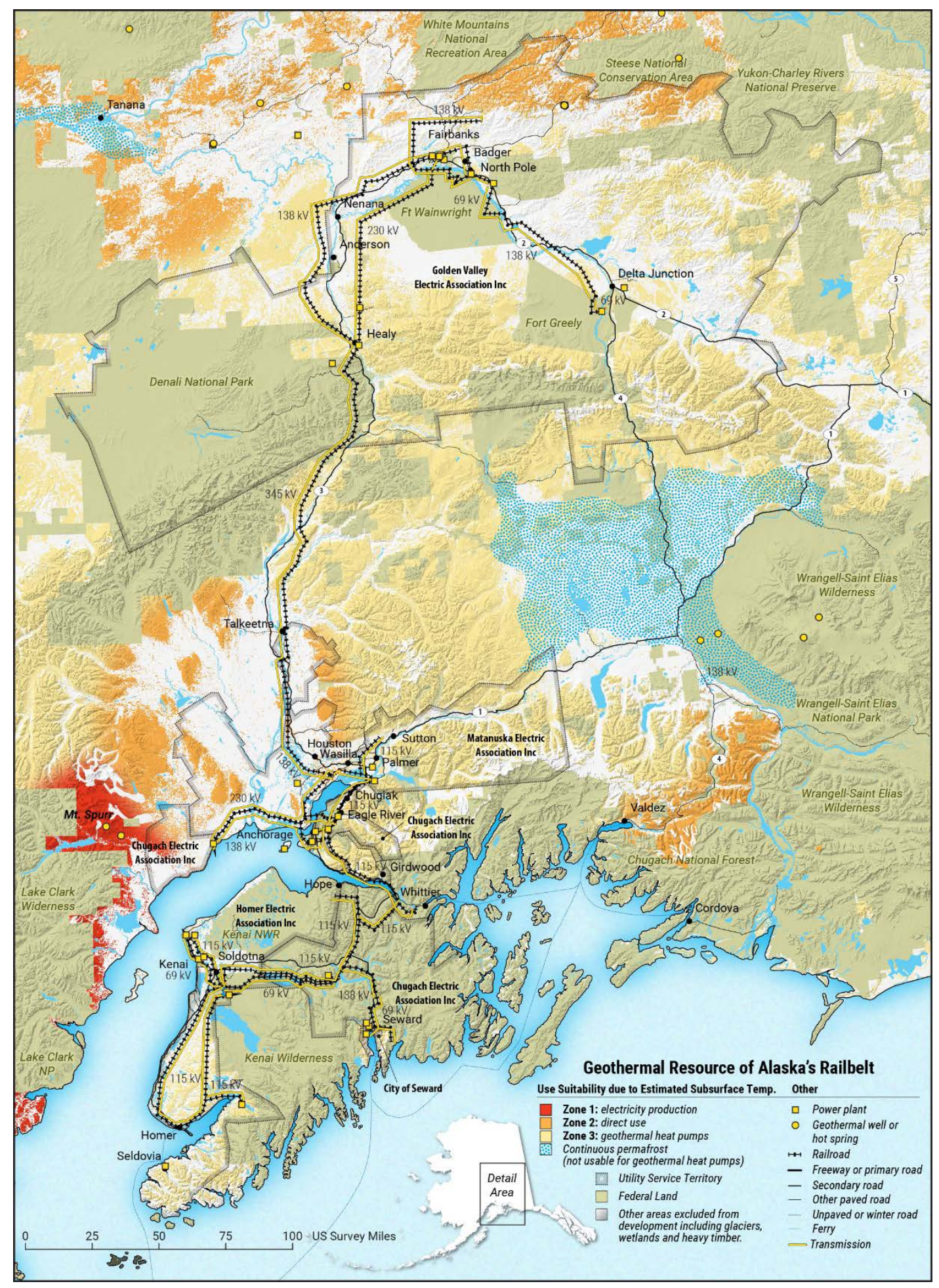

Figure A-1. Geothermal resources of Alaska's Railbelt 


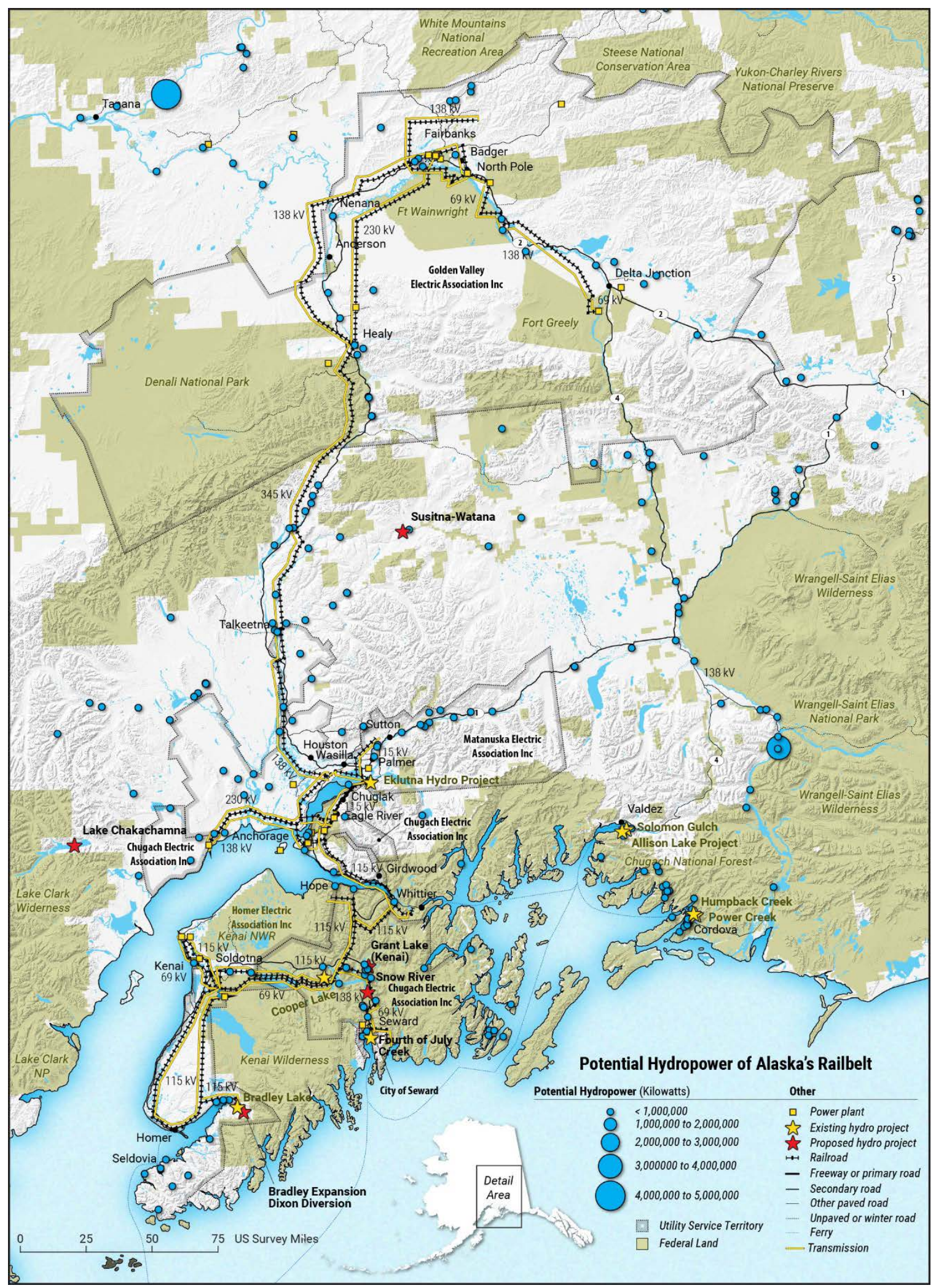

Figure A-2. Potential hydropower of Alaska's Railbelt 


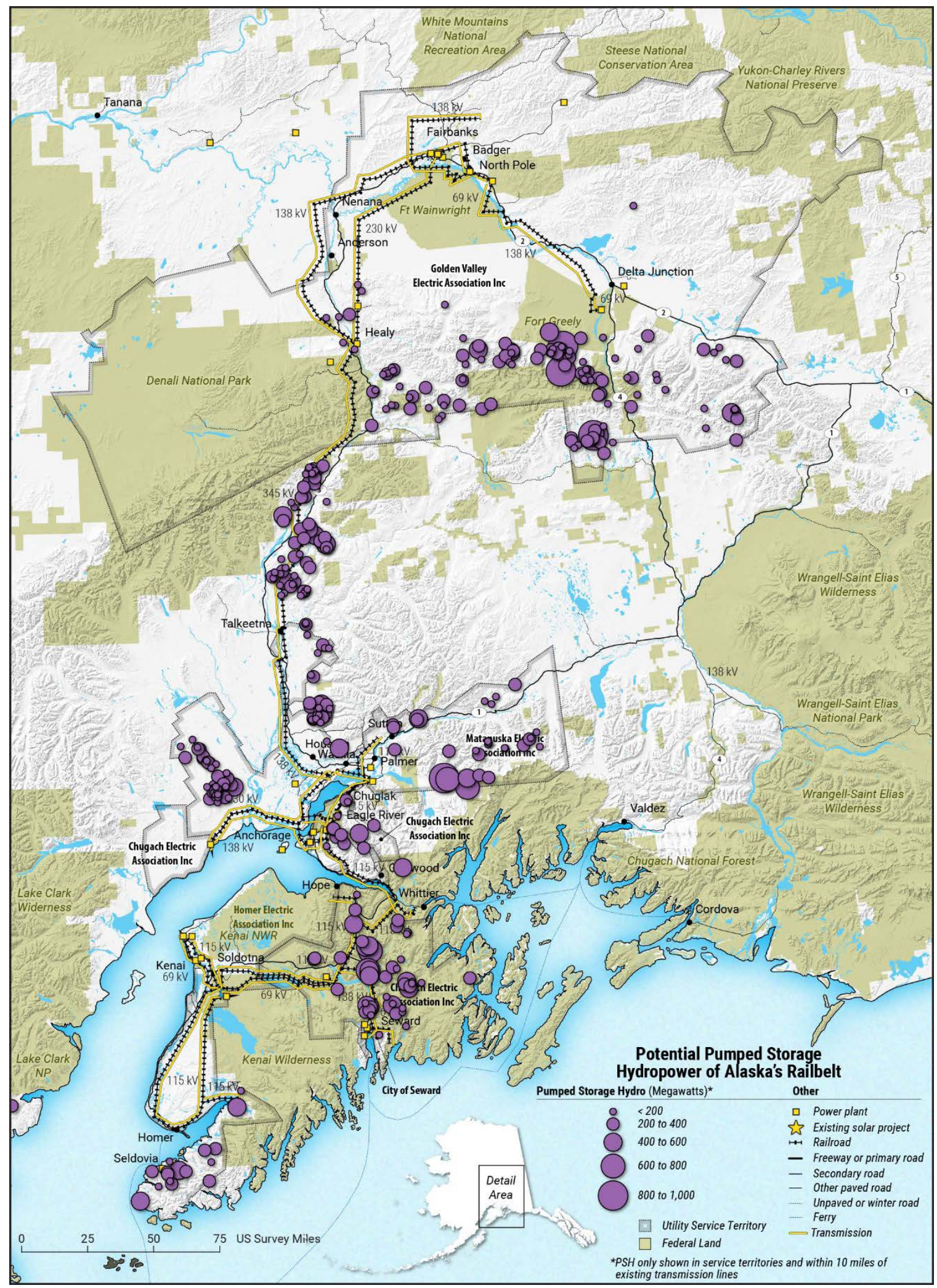

Figure A-3. Potential pumped storage hydropower of Alaska's Railbelt 


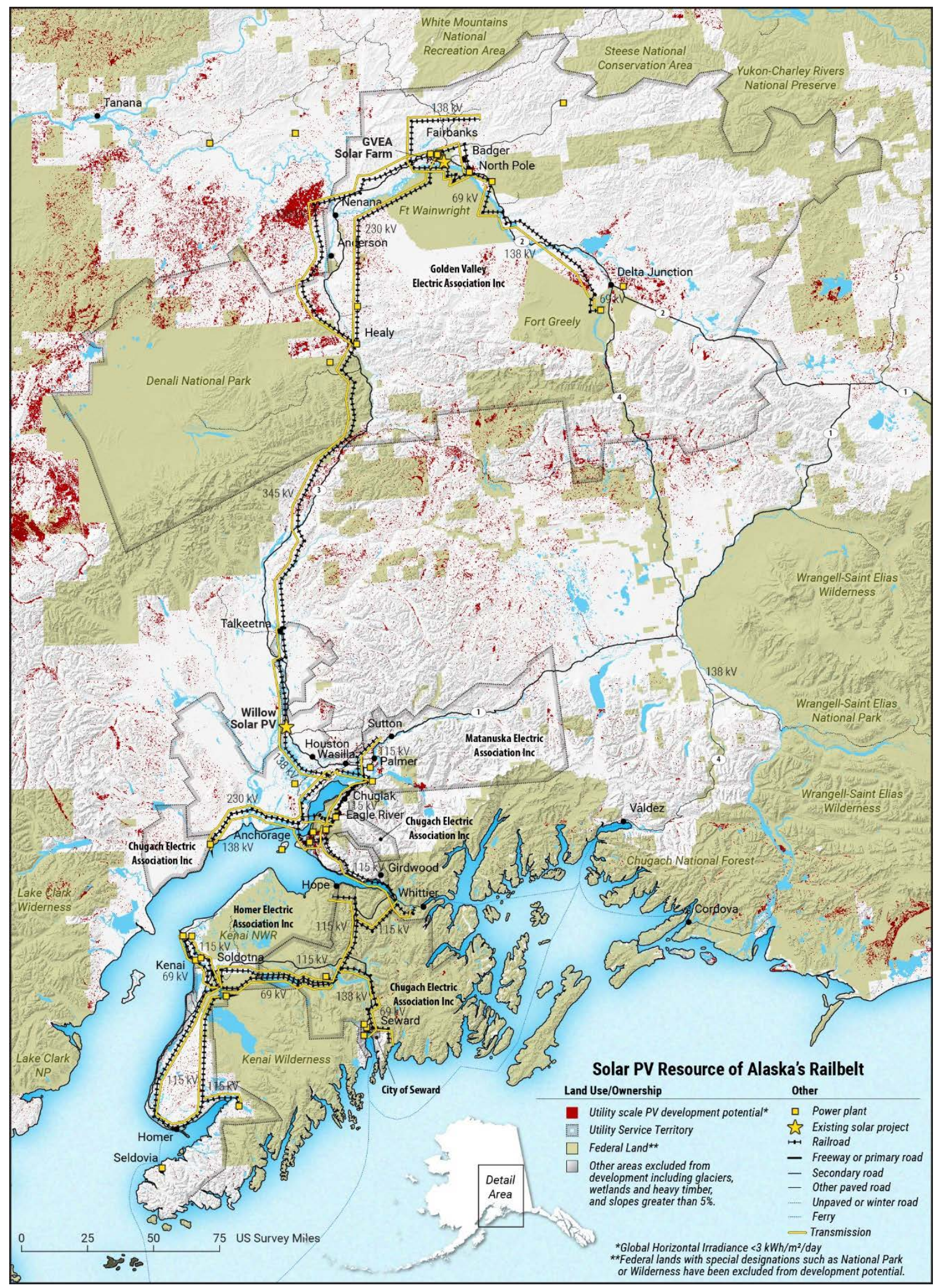

Figure A-4. Solar PV resources of Alaska's Railbelt 


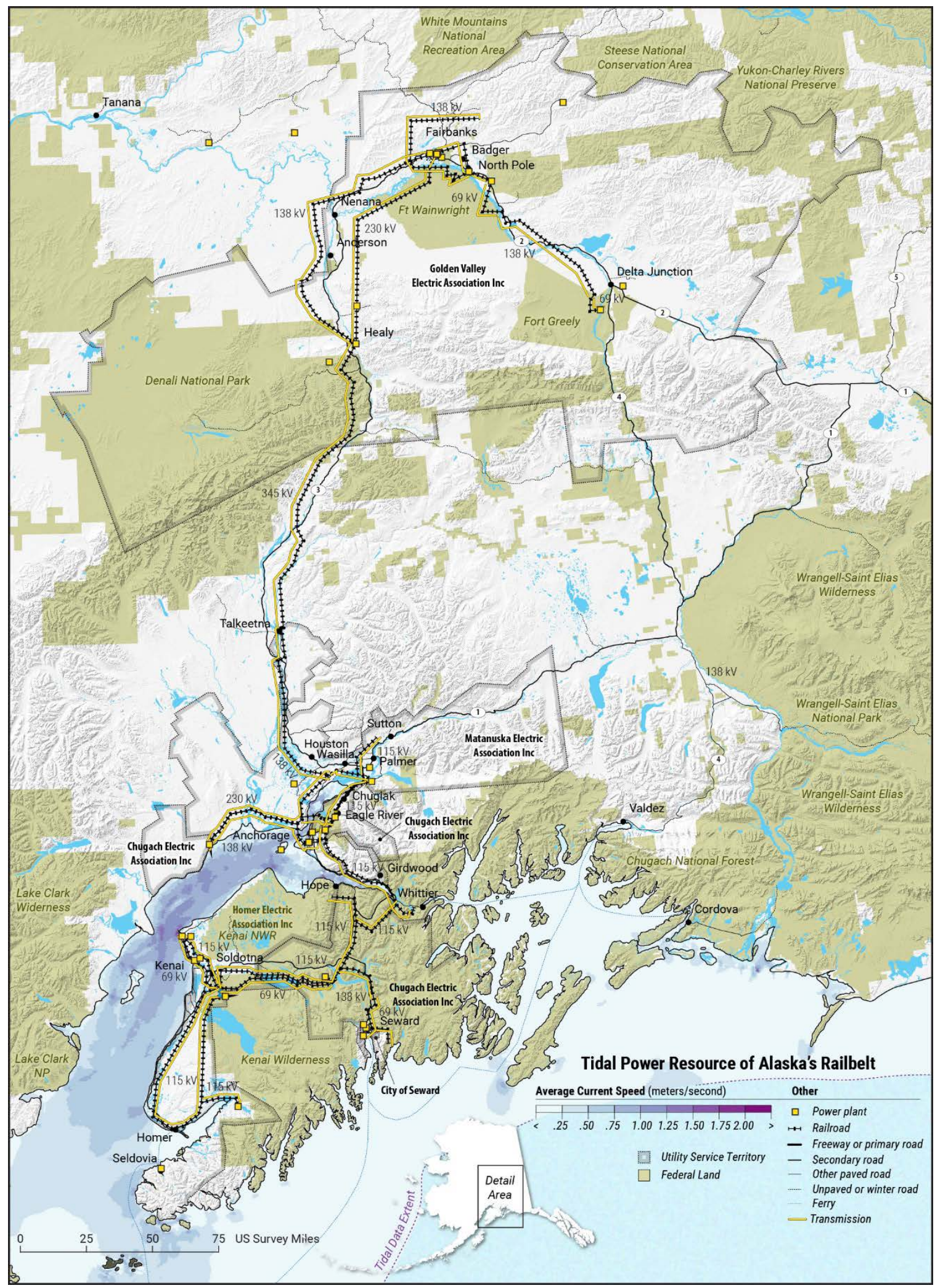

Figure A-5. Tidal resources of Alaska's Railbelt 


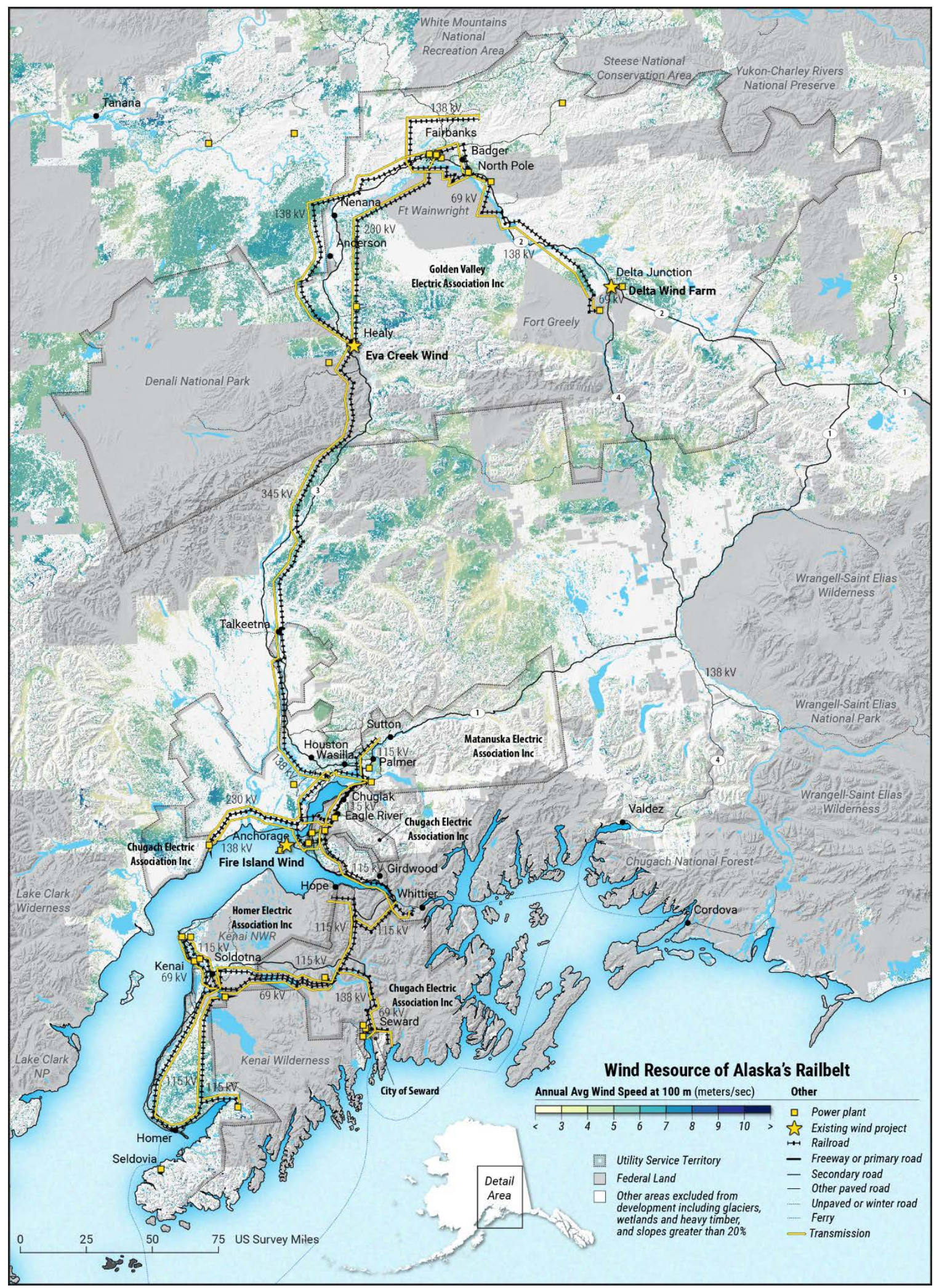

Figure A-6. Wind resource of Alaska's Railbelt 


\section{Appendix B. Performance and Deployment Opportunities by Region along the Alaska Railbelt}

Below are performance and deployment opportunities for each region along the Alaska Railbelt based on information found in the Appendix B resource maps.

\section{Golden Valley Electric Association (GVEA)}

- Solar PV: Areas with utility-scale PV potential include areas east and west of Nenana $(>2.75$ $\mathrm{kwh} / \mathrm{m}^{2} /$ day), east of Delta Junction $\left(>2.75 \mathrm{kWh} / \mathrm{m}^{2} /\right.$ day $)$, Badger and North Pole area $(>2.75$ $\mathrm{kWh} / \mathrm{m}^{2} /$ day), and some areas between the GVEA and Matanuska Energy Association service territories along the Parks Highway $\left(>2.45 \mathrm{kWh} / \mathrm{m}^{2} /\right.$ day$)$.

- Wind: The areas with high potential resources include areas east and west of Nenana and Anderson ( $>6 \mathrm{~m} / \mathrm{s}$ annual average wind speed), East of Delta Junction ( $>6 \mathrm{~m} / \mathrm{s}$ annual average wind speed), and some areas between the GVEA and MEA service territories along the Parks Highway ( $>6 \mathrm{~m} / \mathrm{s}$ annual average wind speed).

- Geothermal: Some opportunities in the Fairbanks area of the GVEA can be applied for direct use. Significant portions of the GVEA territory would be suitable for geothermal heat pumps.

- Pumped-Storage Hydropower: Areas with low (<200 MW) to small (200-400 MW) potential are found near Healy. Areas with moderate (400-600 MW) to high (600-800 MW) potential South of Delta Junction are technically challenging locations.

\section{Matanuska Electric Association (MEA)}

- Hydropower: Areas with utility-scale hydropower potential include areas northeast of Talkeetna (>600 MW).

- Solar PV: Areas with utility-scale PV potential include the foothills east of Willow $(>2.75$ $\mathrm{kW} / \mathrm{m}^{2} /$ day) and the Point MacKenzie area $\left(>2.45 \mathrm{kWh} / \mathrm{m}^{2} /\right.$ day).

- Wind: The area with the best potential wind resource is the Point MacKenzie area $(>7 \mathrm{~m} / \mathrm{s}$ annual average wind speed).

- Geothermal: There are some opportunities in the Point MacKenzie area of the MEA that have utility for direct use

- Pumped-Storage Hydropower: Areas with potentials from low ( $<200 \mathrm{MW})$ to high $(600$ $800 \mathrm{MW}$ ) can be found along the foothills East of the Parks Highway, West of the Point MacKenzie area, North of Wasilla, near Sutton, and other locations along the Glenn Highway.

\section{Chugach Electric Association}

- Hydropower: Areas with utility-scale hydropower potential include an area west of Beluga (>300 MW).

- Solar PV: Areas with utility-scale PV potential include many urban areas of Anchorage, Eagle River, and Chugiak ( $>2.75 \mathrm{kWh} / \mathrm{m}^{2} /$ day $)$.

- Wind: Outside of Fire Island, the best potential wind resource is west of Beluga $(>6 \mathrm{~m} / \mathrm{s}$ annual average wind speed).

- Pumped-Storage Hydropower: Areas with potentials from small (200-400 MW) to high (600-800 MW) include areas near Chugiak, near Eagle River, and east of Anchorage. 
- Tidal Energy: Cook Inlet has one of the United States' leading potential sites for tidal energy generation. Large areas have average current speeds in excess of $1 \mathrm{~m} / \mathrm{s}$, and some areas have average current speeds in excess of $1.5 \mathrm{~m} / \mathrm{s}$.

- Geothermal: Chugach has significant geothermal resources that are well-placed for producing electricity.

- Biomass: The Municipality of Anchorage's landfill gas capture operations has the potential to expand.

Homer Electric Association (HEA)

- Hydropower: Areas with utility-scale hydropower potential include areas east of Razdolna $(<180 \mathrm{MW})$ and east of Cooper Landing $(<5 \mathrm{MW})$.

- Solar PV: HEA has many small, decentralized locations that meet the irradiance requirements for utility-scale PV potential.

- Wind: HEA has a modest number of small, decentralized locations with annual average wind speeds of greater than $5 \mathrm{~m} / \mathrm{s}$.

- Pumped-Storage Hydropower: Areas with potentials from small (200-400 MW) to high (600-800 MW) include areas near Halibut Cove, Nanwalek, Port Graham, Razdolna, and Seldovia.

- Tidal Energy: Cook Inlet has one of the United States' leading potential sites for tidal energy generation. Large areas have average current speeds in excess of $1 \mathrm{~m} / \mathrm{s}$, and some areas have average current speeds in excess of $1.5 \mathrm{~m} / \mathrm{s}$.

\section{City of Seward}

- Hydropower: Areas with utility-scale hydropower potential include areas north of Seward (<70 MW).

- Pumped-Storage Hydropower: Areas with low potential $(<200 \mathrm{MW})$ including areas east of Seward.

Per hydroelectric potential maps of the Alaska Railbelt, there are also dozens of potential small hydropower locations along the Railbelt. These locations could increase energy independence and grid stability by supporting small communities along the Alaska Railbelt. 


\section{Appendix C. Supplemental Information}

\section{Resource Assumptions}

Wind details: Production data is simulated from ERA5 wind re-analysis data from 2000-2020 at $100 \mathrm{~m}$, sped up using annual average wind speeds from UL's 200-m resolution downscaled wind resource models that take into account terrain and other factors. A power curve from the GE 3.4MW/140-m turbine at a hub height of $98 \mathrm{~m}$ was applied to estimate production. Total losses of $17 \%$ are included (electrical losses, turbulence, wake losses, downtime, cold weather package energy consumption, etc.).

Solar: We used profiles generated for 4 locations in Alaska derived from PVWatts for three locations in Alaska (Anchorage, Talkeetna and Fairbanks) using one-axis tracking systems with a 1.4 DC/AC ratio, plus an additional fixed-tilt system in Anchorage. These data sets use older resource data which are not time-synchronized with our meteorological year of 2018 . We obtained a profile for 2018 for the Homer region using the System Advisor Model and data from the National Solar Radiation Database.

\section{Supplemental Dispatch Curves}

The dispatch in the main body (peak day) is a period with relatively good wind. A much better representation of a challenging day is the peak net demand day. This is provided in Figure C-1. 


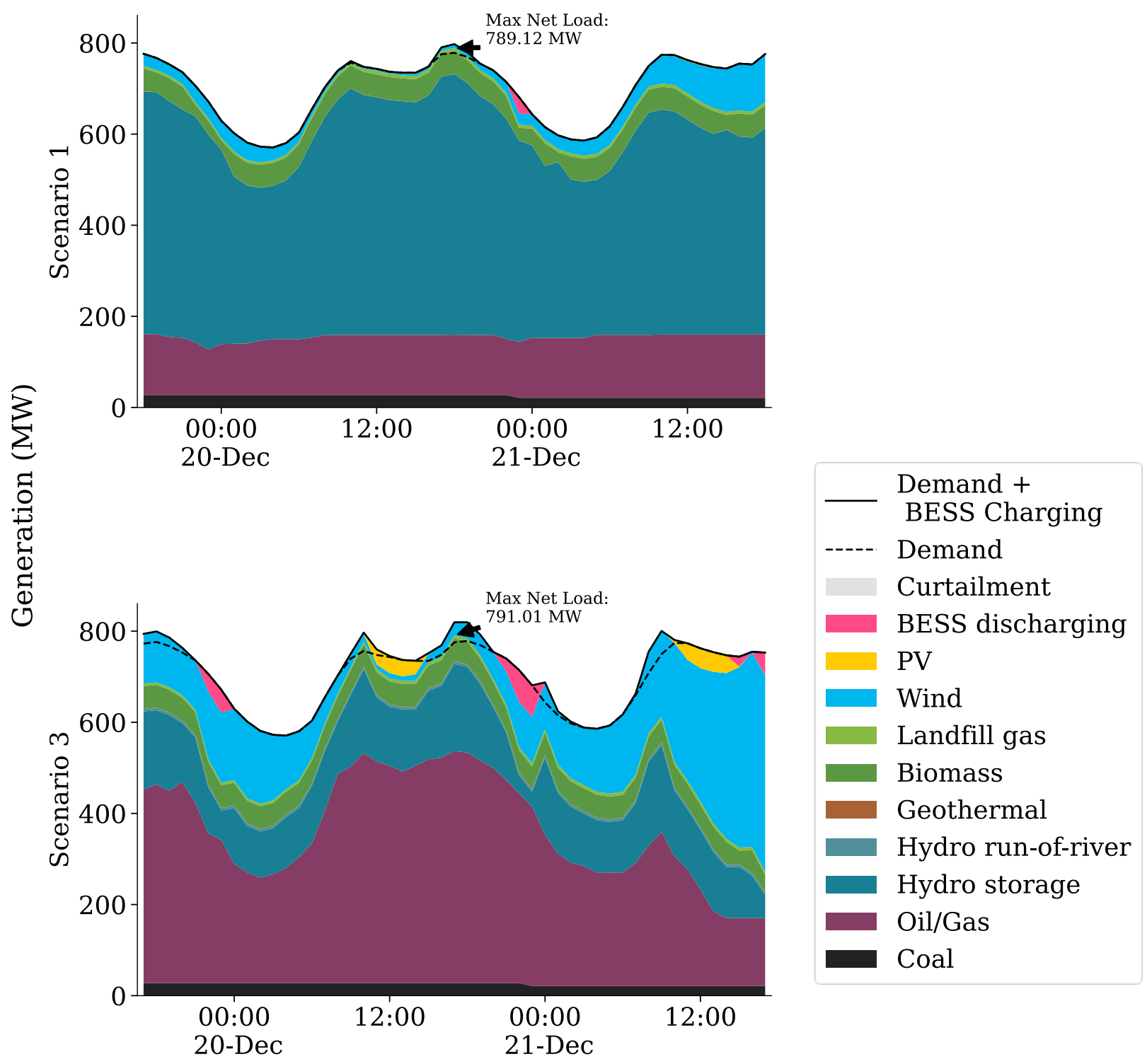

Figure C-1. Dispatch on peak net demand day 